\title{
Development of a chemistry module for GCMs: first results of a multiannual integration
}

\author{
B. Steil ${ }^{1}$, M. Dameris ${ }^{2}$, C. Brühl ${ }^{1}$, P. J. Crutzen ${ }^{1}$, V. Grewe ${ }^{2}$, M. Ponater $^{2}$, R. Sausen ${ }^{2}$ \\ ${ }^{1}$ Max-Planck-Institut für Chemie, Abteilung Luftchemie, D-55020 Mainz, Germany \\ ${ }^{2}$ DLR Institut für Physik der Atmosphäre, Oberpfaffenhofen, D-82234 Weßling, Germany
}

Received 20 February 1997 / Revised: 30 July 1997 / Accepted: 31 July 1997

\begin{abstract}
The comprehensive chemistry module CHEM has been developed for application in general circulation models (GCMs) describing tropospheric and stratospheric chemistry, including photochemical reactions and heterogeneous reactions on sulphate aerosols and polar stratospheric clouds. It has been coupled to the spectral atmospheric GCM ECHAM3. The model configuration used in the current study has been run in an "off-line" mode, i.e. the calculated chemical species do not affect the radiative forcing of the dynamic fields. First results of a 15-year model integration indicate that the model ECHAM3/CHEM runs are numerically efficient and stable, i.e. that no model drift can be detected in dynamic and chemical parameters. The model reproduces the main features regarding ozone, in particular intra- and interannual variability. The ozone columns are somewhat higher than observed (approximately $10 \%$ ), while the amplitude of the annual cycle is in agreement with observations. A comparison with HALOE data reveals, however, a serious model deficiency regarding lower-stratosphere dynamics at high latitudes. Contrary to what is concluded by observations, the lower stratosphere is characterized by slight upward motions in the polar regions, so that some of the mentioned good agreements must be considered as fortuitous. Nevertheless, ECHAM3/CHEM well describes the chemical processes leading to ozone reduction. It has been shown that the mean fraction of the northern hemisphere, which is covered by polar stratospheric clouds (PSCs) as well as the temporal appearance of PSCs in the model, is in fair agreement with observations. The model results show an activation of chlorine inside the polar vortex which is stronger in the southern than in the northern winter hemisphere, yielding an ozone hole over the Antarctic; this hole, however, is also caused to a substantial degree by the dynamics. Interhemispheric differences concerning
\end{abstract}

Correspondence to: Dr. Martin Dameris e-mail: martin.dameris@dlr.de reformation of chlorine reservoir species $\mathrm{HCl}$ and $\mathrm{ClONO}_{2}$ in spring have also been well reproduced by the model.

Key words Atmospheric composition and structure Middle atmosphere $\cdot$ Meteorology and atmospheric dynamics $\cdot$ Climatology $\cdot$ General circulation

\section{Introduction}

The Earth's climate is a complex interactive system involving a variety of non-linear dynamic, physical and chemical processes. Hence, it is difficult to describe and understand the variability of the system, as well as its response to various natural and anthropogenic impacts. Comprehensive models of the whole climate system are needed to address this issue. The improvement of coupled three-dimensional (3D) atmosphere-ocean general circulation models, which treat the problem of global climate change due to anthropogenic carbon dioxide emissions (e.g. Cubasch et al., 1992, 1995; Mitchell et al., 1995), has been one step in developing such a model framework.

Most recently, the problem of coupling dynamic, physical and chemical processes in large-scale climate models has been approached. The inclusion of chemical processes in general circulation models (GCMs) offers new possibilities for climate studies (IPCC, 1995), with ozone playing a key role in this respect. Various human activities influence both stratospheric and tropospheric ozone. In order to estimate respective changes, it is necessary to include not only detailed photo-chemistry but also to consider the effects of heterogeneous chemical reactions on sulphate aerosols and polar stratospheric clouds (PSCs) in the models.

There are several possibilities to carry out coupled 3D model studies considering dynamic and chemical 
processes. One of them is to use relatively comprehensive chemistry codes and to employ observed or precalculated meteorological fields for the calculation of the transport of atmospheric trace constituents (tracers) for shorter time-periods (weeks). For example, Lefèvre et al. (1994) used such a 3D chemical transport model (REPROBUS) of the stratosphere to simulate the evolution of tracers for the European Arctic Stratospheric Ozone Experiment (EASOE) during the Arctic winter 1991/1992. They calculated a 10-20 Dobson Unit (DU) chemical ozone loss over the North Atlantic and Scandinavia in January 1992, which was only a minor fraction of the observed total ozone deficit (approximately 90 DU, Naujokat et al., 1992). Dynamic effects on the ozone column are dominant. Chipperfield et al. (1995) used a similar chemical transport model (SLIMCAT) to analyse some Transall measurements (Blom et al., 1995) of $\mathrm{ClONO}_{2}$ and $\mathrm{HNO}_{3}$ inside the Arctic polar vortex in January, February and March 1993. They could demonstrate that the observed variability in $\mathrm{ClONO}_{2}$ at the end of January can be explained by chemical processing on PSCs and recovery during non-PSC periods. Both Lefèvre et al. (1994) and Chipperfield et al. (1995) employed wind and temperature fields provided by the European Centre for Medium-Range Weather Forecasts (ECMWF) to drive the transport of tracers and to compute their chemical loss and production rates.

Chemical transport models (CTMs) can also be forced by the output of dynamic models (e.g. GCMs). In that case they are mainly used for fundamental theoretical investigations, e.g. to establish a relationship between ozone concentration and particular meteorological parameters (e.g. Grose et al., 1987). Recently, Smith (1995) carried out some simulations with a CTM, taking the dynamics of a mechanistic model of the middle atmosphere to transport trace species to examine the global response to planetary waves in the middle and high latitudes of the northern hemisphere. To forecast the chemical composition field during measurement campaigns, CTMs can be also run over several days using the dynamics provided by operational forecast models. This has been done with success during the Second Stratospheric Arctic and Mid-latitude Experiment (SESAME, 1994-1995) (Lefèvre, Chipperfield, personal communications).

An alternative to the CTM approach is the application of a 3D GCM coupled with a "simplified" chemistry module that takes into account only the most important tropospheric and stratospheric chemical constituents and reactions relevant for a given process (e.g. Köhler et al., 1997). Such global models are useful tools to investigate the evolution of the dynamics and the chemical composition of the atmosphere for longer time-periods (years). If a GCM including chemistry (GCMC) was able to reproduce observed circulation statistics, i.e. mean state, intra- and interannual variability, trends, etc., and past and present chemical composition of the atmosphere, the basis for estimates of future chemical composition and related changes in climate would be laid.
A first step in this direction was made by Cariolle and Deque (1986) with a middle-atmosphere GCM (model top at $80 \mathrm{~km}$ ). They employed a linear parameterization of the ozone photochemistry to simulate the ozone distribution and its variability. Later, Cariolle et al. (1990) used the ozone mixing ratio as a prognostic variable in their GCM. Chemical loss and production of ozone were parameterized (using lifetimes). The ozone field was adopted for the radiative transfer calculations, thus creating an interactive coupling between dynamics, ozone distribution and thermal structure of the stratosphere. In order to analyse the effect of the Antarctic ozone hole, particularly in mid-latitudes, they introduced an extra loss term in the ozone continuity equation, which prescribed the main characteristics of the ozone hole.

Rasch et al. (1995) published results of a middleatmosphere version (model top at $75 \mathrm{~km}$ ) of the NCAR Community Climate Model (CCM) that includes ozone photochemistry. Similar to the model assumption in the present study, the ozone distribution forecast from the chemistry module did not affect the radiative forcing of the dynamic fields. The chemistry module simulated the evolution of 24 chemically reactive gases, including ozone. Only gas phase reactions were considered. Nine long-lived species and four chemical families $\left(\mathrm{NO}_{x}\right.$, $\mathrm{NO}_{y}, \mathrm{O}_{x}, \mathrm{Cl}_{x}$ ) were advected. Results were shown from a 2-year simulation. This simulation was run in a socalled "partially coupled" mode, i.e. the predicted water-vapour distribution was determined both by dynamics and chemical production of water vapour by methane oxidation. Simulated distributions of the longlived species $\mathrm{N}_{2} \mathrm{O}$ and $\mathrm{CH}_{4}$ were in good agreement with corresponding satellite observations. The latitudinal variation and seasonal evolution of the ozone column abundance were reproduced quite realistically, but the calculated vertical distribution of the ozone mixing ratio showed clear differences with observations, especially in the upper stratosphere. Since the southern-hemisphere polar vortex was too persistent and too strong, the calculated polar ozone columns were too low during the whole model simulation (not enough transport of ozone from mid-latitudes).

Eckman et al. (1995) used the NASA Langley 3D GCM coupled to a comprehensive chemistry module to investigate long-term model stability. They performed a 7 -year model run employing only gas phase chemistry. An extra 1-year simulation, additionally considering parameterized heterogeneous processes on PSCs and reactions occuring on sulphate aerosols, was carried out. Heterogeneous processes on PSCs occurred when the calculated temperature was less than $195 \mathrm{~K}$ and air pressure greater than $20 \mathrm{hPa}$. The parameterization of the PSC formation was thus decoupled from the model's $\mathrm{H}_{2} \mathrm{O}$ and $\mathrm{HNO}_{3}$ distributions, and no distinction was made between type-I and type-II PSCs. Three chemical families $\left(\mathrm{NO}_{y}, \mathrm{O}_{x}, \mathrm{Cl}_{y}\right)$ and twelve individual constituents were explicitly transported by the model. The model was run in an "off-line" mode, i.e. the chemistry was run without influencing the dynamic simulation at all. In comparison to observations from the Upper Atmo- 
sphere Research Satellite (UARS), the Eckman et al. model performed well in describing the latitudinal and seasonal variation of total ozone. Nevertheless, the southern polar ozone depletion was less deep and longer lived than observed. At high latitudes, calculated $\mathrm{HNO}_{3}$ concentrations only agreed with observations when reactions on sulphate aerosol were included. $\mathrm{ClONO}_{2}$ measurements showed obvious differences with model results. Eckman et al. argued that some shortcomings could be explained by insufficient horizontal model resolution (T16) and, in some areas, an inadequate description of chemical processes. Nevertheless, Eckman et al. (1996) used this model to investigate the transfer of ozone-poor air from the polar region following the break-up of the southern-hemisphere polar vortex. The results of two 5-year model simulations were compared, one simulation considering only gas phase and sulphate aerosol chemistry, the second additionally including heterogeneous reactions on PSCs. For example, they found that a potential exists for a long-term accumulation of ozone loss in the southern polar region and a gradual increase in the global impact of polar ozone depletion.

To investigate the distribution and budget of ozone in the troposphere, Roelofs and Lelieveld (1995) coupled the atmospheric general circulation model ECHAM3 (also used for the present study) with a chemistry module describing background tropospheric $\mathrm{CH}_{4}-\mathrm{CO}-$ $\mathrm{NO}_{x}-\mathrm{HO}_{x}$ photochemistry. The tropospheric chemistry scheme did not fully account for ozone production/ destruction in the stratosphere. Stratospheric concentrations of $\mathrm{O}_{3}$ and $\mathrm{NO}_{y}$ were prescribed as boundary conditions for the troposphere. Roelofs and Lelieveld analysed the last two years of a 3-year model simulation. They found strong seasonal variations in stratospheretroposphere exchange of ozone, with a maximum during winter and spring, and a summer maximum in the photochemical production and destruction of ozone. Tropospheric ozone concentrations near the poles and in polluted areas were underestimated by the model. The authors supposed that this could be caused by too weak transport from mid to high latitudes and by the inadequate representation of tropopause folds in the ECHAM model, with a T21 horizontal resolution and a vertical resolution of approximately $2 \mathrm{~km}$ near the tropopause.

The current paper aims to introduce the coupled dynamic-chemical general circulation model ECHAM3/ CHEM. In some ways, in particular concerning the description of heterogeneous processes, it differs from recently published approaches. In the following section, the newly developed chemistry module CHEM will be described in detail, and a brief review of the main characteristics of ECHAM3 will be given. First results of a multiannual "off-line" integration (15 years) will be presented and discussed in Sect. 3. A comparison with HALOE data will provide the basis for a discussion of abilities and deficiencies of the model. Section 4 contains concluding remarks and an outlook.

\section{Model description}

\subsection{The GCM ECHAM3}

On the basis of a previous version of the numerical weather prediction model of the ECMWF, the spectral atmospheric general circulation model ECHAM3 (ECMWF model, Hamburg version 3) has been developed with emphasis on climate change (Roeckner et al., 1992). Prognostic variables are vorticity, divergence, temperature, surface pressure, water vapour, cloud water and up to 16 different tracers (optional). Winds are diagnosed from the variables of vorticity and divergence. We applied a slightly modified version of the operational ECHAM3 model, in which water vapour, cloud water and the tracers are advected by a semi-Lagrangian transport (SLT) scheme employed in the grid-point domain (Rasch et al., 1995). The SLT scheme instead of the operational Eulerian advection scheme is used to avoid negative concentrations. Since it is not conserving mass, a mass-fixer has been used (Rasch and Williamson, 1990). The operational spectral advection scheme is used for the remaining prognostic variables. ECHAM3 contains state-of-the-art parameterizations of radiation, cloud formation and precipitation, convection (including tracers), vertical and horizontal diffusion, and land surface processes.

ECHAM3 has 19 vertical layers (L19), using a hybrid $\sigma$-p coordinate system. The uppermost model layer is centred at $10 \mathrm{hPa}$, the lowermost layer approximately at $30 \mathrm{~m}$ above the surface. For economic reasons, a spectral T21 horizontal resolution was chosen, corresponding to a resolution for dynamic processes of approximately $1000 \mathrm{~km}$. The associated Gaussian transform grid, which is also used for the SLT scheme, has a resolution of about $5.6^{\circ}$. A T21/L19 resolution of ECHAM model versions is sufficient to yield a realistic simulation of the mean state and variability (Roeckner et al., 1992; König et al., 1993). Larger systematic errors occur, however, in the lower stratosphere (see Roeckner et al., 1992, Figs. 6 and 7): for example, in the winter northern hemisphere the model temperature is generally too cold, whereas in the winter southern hemisphere the sign of the temperature bias alternates, with too cold temperatures below $150 \mathrm{hPa}$ and above $30 \mathrm{hPa}$ and too warm temperatures between these two pressure levels. During recent years various versions of ECHAM have been successfully employed in several climate sensitivity, climate change and tracer transport experiments (e.g. Feichter et al., 1991; Cubasch et al., 1992; Sausen and Köhler, 1994; Boucher and Lohmann, 1995; Graf et al., 1995; Lunkeit et al., 1996; Ponater et al., 1996).

\subsection{The chemistry module CHEM}

Taking the Mainz 2D chemistry model (Brühl and Crutzen, 1993) as a basis, a comprehensive 3D chemistry module with a numerical scheme appropriate for subsequent use in GCMs has been developed. It is 
based on the "family concept", which combines related chemical constituents with short lifetimes (shorter than that of the dynamics or the model time-step used) into one family with a life-time larger than the time-step. The chemical tendencies are calculated at the grid points. The module runs with a semi-implicit, mass-conserving, positive definite integration scheme, together with a number of steady-state assumptions for species with very short chemical lifetimes, i.e. species within a family. One advantage of this chemistry module is that it can be integrated stably with relatively large time-steps of up to $2 \mathrm{~h}$, which makes it computationally economic. In the framework described here the time-step has been chosen to be the same as the dynamic time-step of ECHAM3 in T21 resolution, i.e. $40 \mathrm{~min}$. The model handles a comprehensive chemical system, involving 107 photochemical reactions and 37 species, for long-term integrations of the $3 \mathrm{D}$ circulation model. In Appendix A all gas phase, heterogeneous and photolytic reactions employed in the model are listed.

The chemistry module CHEM integrates, taking into account both dynamics and chemistry, the following chemical species and families:

$\mathrm{CH}_{4}, \mathrm{~N}_{2} \mathrm{O}, \mathrm{HCl}, \mathrm{H}_{2} \mathrm{O}_{2}, \mathrm{CO}, \mathrm{CH}_{3} \mathrm{O}_{2} \mathrm{H}, \mathrm{ClONO}_{2}, \mathrm{O}_{x}$, $\mathrm{NO}_{x}, \mathrm{ClO}_{x}$,

$\mathrm{HNO}_{3}+$ type I PSC (NAT: $\left.\mathrm{HNO}_{3} \cdot 3 \mathrm{H}_{2} \mathrm{O}\right), \mathrm{H}_{2} \mathrm{O}+$ type II PSC (water ice),

with

$\mathrm{ClO}_{x}=\mathrm{Cl}+\mathrm{ClO}+\mathrm{ClOH}+2 \cdot \mathrm{Cl}_{2} \mathrm{O}_{2}+2 \cdot \mathrm{Cl}_{2}$,

$\mathrm{NO}_{x}=\mathrm{N}+\mathrm{NO}+\mathrm{NO}_{2}+\mathrm{NO}_{3}+2 \cdot \mathrm{N}_{2} \mathrm{O}_{5}+\mathrm{HNO}_{4}$, $\mathrm{O}_{x}=\mathrm{O}_{3}+\mathrm{O}\left({ }^{3} \mathrm{P}\right)+\mathrm{O}\left({ }^{1} \mathrm{D}\right)$.

The different phases of $\mathrm{HNO}_{3}$ and $\mathrm{H}_{2} \mathrm{O}$ are transported together for stability reasons. In the following, $\mathrm{ClOX}$ will denote the sum of $\mathrm{ClO}_{x}$ and $\mathrm{ClONO}_{2}$ and $\mathrm{NOX}$ the sum of $\mathrm{NO}_{x}$ and $\mathrm{ClONO}_{2}$. The concentrations of the family members are integrated taking into account only chemistry, or are analytically calculated, i.e. assumed to be in photochemical steady state. Intermediate products of the methane oxidation, $\mathrm{CH}_{2} \mathrm{O}, \mathrm{CH}_{3} \mathrm{O}_{2}, \mathrm{CH}_{3} \mathrm{O}$ and the $\mathrm{HO}_{x}$-family $\left(=\mathrm{H}+\mathrm{OH}+\mathrm{HO}_{2}\right)$, are computed at each time-step from diagnostic equations considering chemistry only. Details of the numerical method used in the model to calculate the tendencies of chemical species and the chemical solution technique are described in Appendix B. The feasibility of the method has been tested extensively by comparison with results from the quasi-exact chemical solver FACSIMILE (Curtis and Swetenham, 1987).

The annual cycle of the most important source gases for Cl-radicals in the stratosphere (natural and anthropogenic), i.e. $\mathrm{CCl}_{4}, \mathrm{CFCl}_{3}, \mathrm{CF}_{2} \mathrm{Cl}_{2}, \mathrm{CH}_{3} \mathrm{Cl}, \mathrm{CH}_{3} \mathrm{CCl}_{3}$, are prescribed according to results of a transient integration with the Mainz 2D model. The concentrations are given as a function of latitude, height and season, representing the year 1990. They do not change during the model simulation. At $10 \mathrm{hPa}$ the mixing ratios for $\mathrm{NOY}\left(=\mathrm{NOX}+\mathrm{HNO}_{3}\right)$ and $\mathrm{ClX}(=\mathrm{ClOX}$ $+\mathrm{HCl})$ are specified according to the simulation with the 2D model (Grooß, 1996). For the other long-lived species it is assumed that there is no flux across the upper boundary.

Since the model does not include an explicit consideration of methane $\left(\mathrm{CH}_{4}\right)$ emissions, the volume mixing ratios are prescribed at the lower boundary of the model with $1.75 \mathrm{ppmv}$ in the northern hemisphere and $1.63 \mathrm{ppmv}$ in the southern hemisphere, which are representative for the conditions at the beginning of the present decade. Since the emissions of carbon monoxide $(\mathrm{CO})$ in the atmosphere are not well known, the $\mathrm{CO}$ mixing ratio at the Earth surface, which is much better known, is also prescribed in the model as a function of latitude and season (Hein, 1994; DianovKlokov and Yurganov, 1981; Dianov-Klokov et al., 1989).

The description of PSCs in CHEM is formulated largely self-consistently with a minimum of parameterizations. The scheme does not contain any detailed microphysics, but it does distinguish between type-I and type-II clouds. To simulate the observed denitrification in the polar stratosphere, a simplified scheme for the sedimentation of NAT and water ice particles is applied. The description of the PSCs is based on the "classical" mechanism proposed by Poole and McCormick (1988). It is assumed that the formation of NAT takes place on frozen stratospheric sulphuric acid aerosols (most likely sulphuric acid tetrahydrate, $\mathrm{SAT}=\mathrm{H}_{2} \mathrm{SO}_{4} \cdot 4 \mathrm{H}_{2} \mathrm{O}$ ) by bimolecular heterogeneous nucleation of $\mathrm{HNO}_{3}$ and $\mathrm{H}_{2} \mathrm{O}$. Type-II PSCs are formed by heterogeneous unimolecular nucleation of water vapour on NAT particles if temperature falls below the frost point. In reality the mechanisms are more complicated, since sulphate aerosol does not freeze during cooling (Luo et al., 1994). However, sensitivity studies with a box model have shown that the differences with respect to ozone depletion are generally small (Brühl et al., 1997).

The model temperature and mixing ratios of $\mathrm{HNO}_{3}$ and $\mathrm{H}_{2} \mathrm{O}$ are used, together with the algorithm of Hanson and Mauersberger (1988), to predict when PSCs are thermodynamically possible and to calculate the resultant equilibrium gas phase mixing ratios of $\mathrm{HNO}_{3}$ and $\mathrm{H}_{2} \mathrm{O}$. To account for the observed supersaturation required to start the formation of NAT particles (Schlager et al., 1990; Peter et al., 1991; Dye et al., 1992), a nucleation barrier is prescribed. If there are no NAT particles in a grid box at the beginning of a timestep, an offset temperature of $\Delta \mathrm{T}_{N A T, n u c}=3 \mathrm{~K}$ is added on to the actual model temperature to calculate the equilibrium gas phase mixing ratio of $\mathrm{HNO}_{3}$. The calculation of surface and radius of the NAT particles requires three additional assumptions. Type-I particles are assumed to be spherical with a monodisperse size distribution. The particle number density is proposed to be $\mathrm{n}_{N A T}=1 \mathrm{~cm}^{-3}$ (Drdla and Turco, 1991). Prescribing $\mathrm{n}_{N A T}$ instead of a fixed radius for NAT particles prevents the calculated NAT surfaces (and the reaction rates of the heterogeneous reactions) to be too strongly dependent on the chosen parameterization. Finally it is assumed that NAT particles are not existent beyond a minimal radius of $r_{N A T, \text { min }}=0.07 \mu \mathrm{m}$, which is the typical size of the SAT particle that acts as condensation 
core. The formation of type-II PSCs is described in a similar way with $\Delta \mathrm{T}_{i c e, n u c}=1.8 \mathrm{~K}$ (Peter, personal communication), $\mathrm{n}_{i c e}=0.1 \mathrm{~cm}^{-3}$ (Drdla and Turco, 1991) and $\mathrm{r}_{\text {ice, } \min }=0.7 \mu \mathrm{m}$.

According to Wofsy et al. (1990), ice particles form on NAT. Therefore, the sedimentation velocity of NAT and ice particles is assumed to be identical if ice is present, since all NAT is inside the ice, else sedimentation is neglected. The Stokes velocity of ice particles is calculated every time-step according to the changing radius due to condensation or evaporation of water vapour.

The stratospheric sulphuric acid aerosol surface areas are based on a lower limit case (background aerosol conditions, coarse zonal average) of WMO (1992). The enlargement of the aerosol surface areas due to admittance of water (deliquesence) at very low temperatures is considered interactively (Luo et al., 1996).

To determine the photolysis rates, the same procedure is used as in the Mainz 2D model (Brühl and Crutzen, 1989); 176 spectral intervals between 177 and $850 \mathrm{~nm}$ are considered. Albedo, Rayleigh scattering and Mie scattering on aerosols and clouds, as well as absorption by gases $\mathrm{O}_{2}, \mathrm{O}_{3}, \mathrm{NO}_{2}, \mathrm{HNO}_{3}, \mathrm{HNO}_{4}$ and $\mathrm{ClONO}_{2}$ are taken into account. The photolysis rates are interactively determined from the calculated absorber concentrations. Temperature, pressure, cloud cover and albedo are obtained from the GCM. Ozone columns above $10 \mathrm{hPa}$ are taken from the $2 \mathrm{D}$ model, which are also included in the calculated model ozone columns (Sect. 3.1.). To save computer time, the photolysis rate calculations are carried out only every third day and for eight longitudinal sectors of $45^{\circ}$ width using average values for absorbers, aerosol, clouds and albedo. Diurnal cycle is taken into account.

The emissions of $\mathrm{NO}_{x}$ in the troposphere are adopted from Dentener and Crutzen (1993). They depend on season, latitude, longitude and height. The total emissions are assumed to be $40 \mathrm{Tg} \mathrm{N} /$ year $\left(\mathrm{Tg}=10^{12} \mathrm{~g}\right)$, with $20 \mathrm{Tg} \mathrm{N} /$ year by industry and automobile traffic, $4 \mathrm{Tg} \mathrm{N} /$ year by lightning (between surface and tropopause with a maximum emission near $850 \mathrm{hPa}$ ), $10 \mathrm{Tg}$ $\mathrm{N} /$ year by soil microbial production and $6 \mathrm{Tg} \mathrm{N} /$ year by biomass burning. Aircraft emissions are not included here. Dry deposition of $\mathrm{HNO}_{3}, \mathrm{NO}_{x}, \mathrm{HCl}, \mathrm{H}_{2} \mathrm{O}_{2}$ and $\mathrm{O}_{3}$ are treated as in the 3D transport model MOGUNTIA (Zimmermann, 1988) in the version of Dentener and Crutzen (1993). For $\mathrm{O}_{3}$ over sea, half the cited value is used, $\mathrm{HCl}$ is assumed to behave like $\mathrm{HNO}_{3}$. Wet deposition of $\mathrm{HNO}_{3}$ and $\mathrm{HCl}$ is parameterized using the calculated cloud cover and precipitation (Roelofs and Lelieveld, 1995).

\section{Results}

In this section we present results of a 15-year ECHAM3/ CHEM integration with the main intention of studying the general performance of the model over longer timeperiods. The model has been run in an "off-line" mode, i.e. the calculated chemical species do not affect the radiative forcing of the dynamic fields. The coupled model configuration explained in the preceding is run in a numerically efficient way, which was the very reason for its development. However, it is by no means selfevident that the use of a time-step for chemical processes as large as $40 \mathrm{~min}$ will result in stable tracer distribution, i.e. that the model drift will remain limited to a (welldefined) spin-up period. Nor is it obvious that the model will produce physically reasonable results. In fact, earlier versions did not. Although the spin-up time of the model is approximately 2 years, for safety reasons only the model results of the 11-year period from model years 5 to 15 are considered.

\subsection{Mean values of the ozone column}

Figure 1a shows the calculated 11-year mean annual cycle (years 5 to 15 ) of the distribution of the ozone
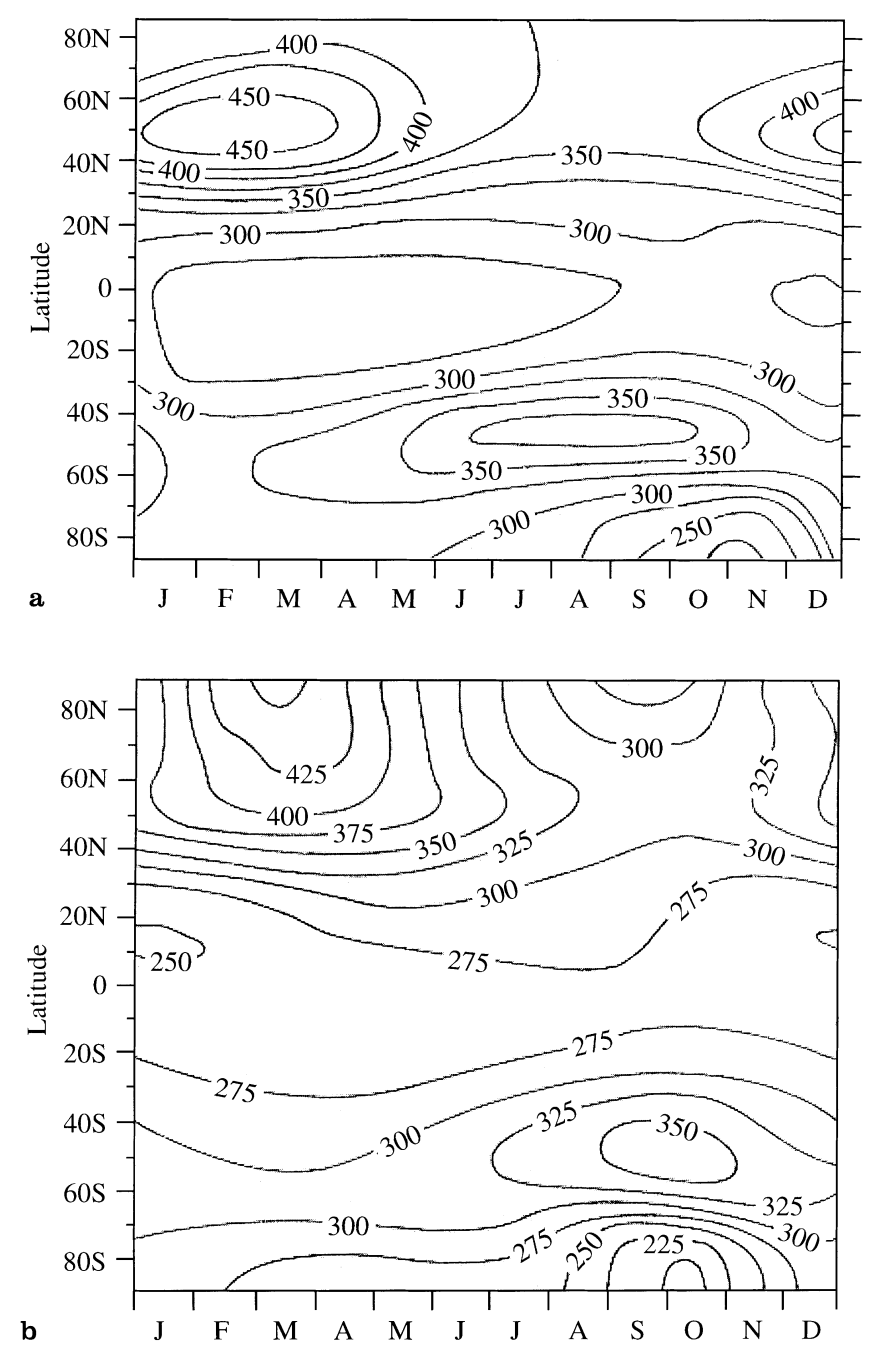

Fig. 1. a Variation of total ozone with latitude and season (in Dobson Units: DU); 11-year mean values of a simulation with ECHAM3/CHEM. b Variation of total ozone with latitude and season (in DU) for the time-interval 1984-1993, based on Global Ozone Observing System $\left(\mathrm{GO}_{3} \mathrm{OS}\right)$ stations (reproduced from Bojkov and Fioletov, 1995). The contour interval is $25 \mathrm{DU}$ 
column. For comparison, respective observations based on total ozone data compiled from over 150 Global Ozone Observing System $\left(\mathrm{GO}_{3} \mathrm{OS}\right)$ stations from 1984 to 1993 are presented (Fig. 1b, reproduced from Bojkov and Fioletov, 1995). In the northern hemisphere, the model reproduces the main features of the annual cycle of total ozone, with a maximum in the winter/spring season and a minimum in summer/autumn. Total ozone is overestimated by up to about 20-50 DU. The position of the ozone maximum in the model is shifted towards lower latitudes $\left(\approx 50^{\circ} \mathrm{N}\right)$, indicating reduced transport towards polar latitudes (see forthcoming discussion). Calculated total ozone values at mid to high latitudes are about $50 \mathrm{DU}$ too high in autumn. At the equator, the ozone columns are higher than observed by $10-20$ DU.

The development of an ozone hole over the Antarctic in spring has been modelled. The absolute values of total ozone of the model are somewhat too high in the polar region: observations for October indicate values below 200 DU, whereas the simulated ozone columns at the end of October/beginning of November range between 225 and 200 DU. Here it must be pointed out that the present model configuration ignores bromine chemistry, which will be one reason for too little ozone loss (see also discussion). In contrast to the somewhat delayed ozone hole development in the southern hemisphere, the mid-latitude ozone maximum occurs about 6 weeks too early in the simulation.

Differences between the modelled and observed ozone distributions (especially during winter and early spring) can partly be explained by systematic errors of the model with respect to stratospheric dynamics. In the northern hemisphere, the model tends to produce a too cold and therefore too stable polar winter vortex centred around the pole (cf. Roeckner et al., 1992). This reduces tracer transport from mid to high latitudes, resulting in an ozone maximum in spring in mid-latitudes and somewhat too low column ozone values in the polar region (Fig. 1). The lower temperatures inside the vortex should also lead to enhanced PSC formation. This is prevented only by a fortuitous compensation of errors (see Sect. 3.4.). The lower stratosphere is not only too cold, but also too dry in the model. A long-term mean zonally averaged value of $\mathrm{H}_{2} \mathrm{O}$ volume mixing ratio of approximately $3 \mathrm{ppmv}$ is found at $50 \mathrm{hPa}$ in the polar winter area (not shown). Measurements (1991-1993) by the Microwave Limb Sounder (MLS) on UARS (Elson et al., 1996) indicate values of $\mathrm{H}_{2} \mathrm{O}$, which are greater than 4.8 ppmv during wintertime polewards of $70^{\circ} \mathrm{N}$ at $46 \mathrm{hPa}$ and greater than $6 \mathrm{ppmv}$ inside the polar vortex (HALOE on UARS, Harries et al. (1996), and Russell, personal communication). Since the model is run in an off-line mode, the reason for the lack of water vapour is that the amount of stratospheric water vapour is determined only by the vertical transport from the troposphere into the stratosphere, while the chemical production of $\mathrm{H}_{2} \mathrm{O}$ in the stratosphere by methane oxidation (yielding about two molecules of $\mathrm{H}_{2} \mathrm{O}$ per methane molecule oxidized and beginning with an $\mathrm{OH}$ reaction) is not taken into account.
During late northern-hemispheric summer, the model shows ozone values larger than observed (Fig. 1). This discrepancy can also be mostly explained by the fact that the model lower stratosphere contains less water vapour than observed. Model values of approximately 3 ppmv (zonally averaged value) are calculated, whereas observations by MLS show values significantly larger than 4 ppmv (Elson et al., 1996). This yields smaller $\mathrm{OH}$ concentrations in the model (not shown), which in turn leads to a smaller ozone destruction rate (since below $20 \mathrm{~km}$ the odd hydrogen catalytic cycles are dominant).

In the southern hemisphere, the model reproduces the formation of the ozone hole quite well. Nevertheless, the total ozone columns calculated by the model are too high, both in the polar region and at mid-latitudes. One reason for this could be that model temperatures deviate from observations during Austral spring, especially at the $50-\mathrm{hPa}$ pressure level. Figure 2 (bottom) shows
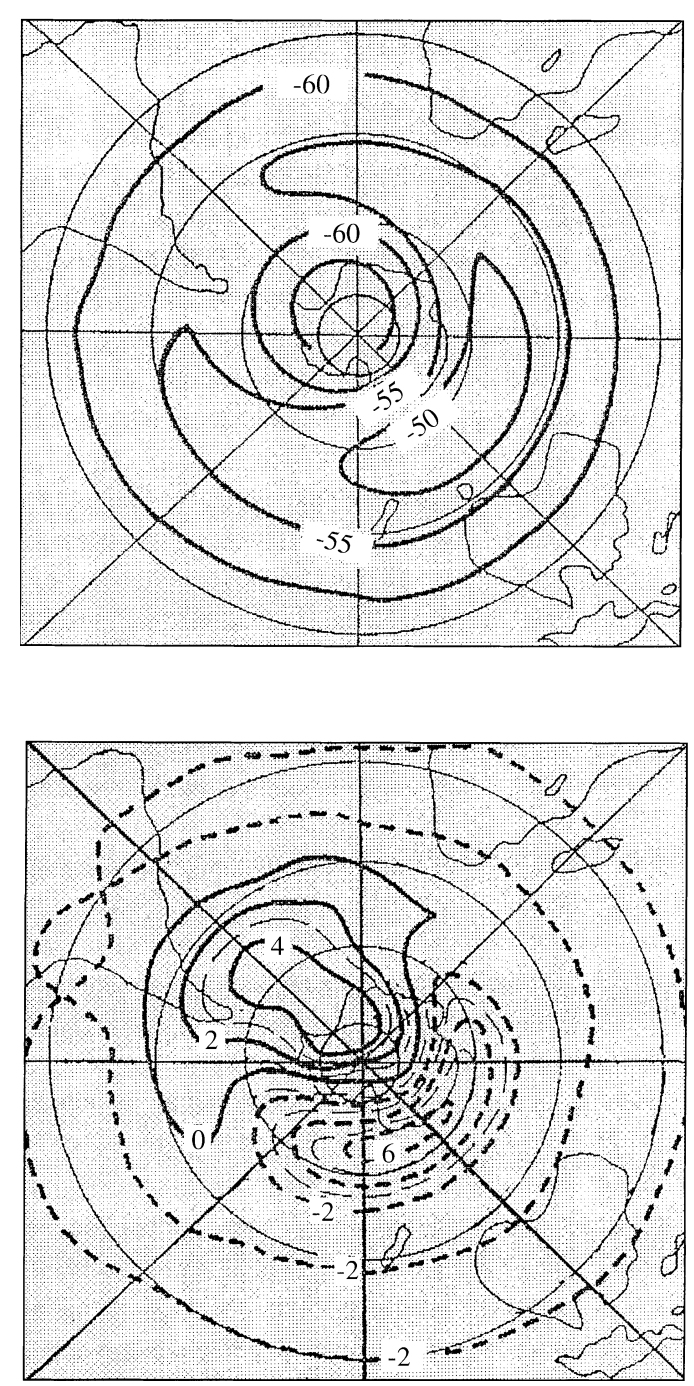

Fig. 2. 10-year mean of southern-hemisphere September, October, November (SON) time-average 50-hPa temperature field (1980-1989) from ECMWF analyses (upper panel). Southern-hemisphere SON time-average $50-\mathrm{hPa}$ temperature differences between the ECHAM3/ CHEM simulation and ECMWF analyses (lower panel). ECMWF data are subtracted from model values 
temperature differences at $50 \mathrm{hPa}$ of 10 -year means of ECMWF analyses and model results for the September, October, November time-average. A "dipole" structure is found with the mean model temperature being too high $(5 \mathrm{~K})$ in the area of the Antarctic temperature minimum (Fig. 2, top) and too low (-6 K) near the region of maximum temperatures. Therefore, the amplitude of the wave number 1 structure in the temperature field is reduced in the model. The warm bias of the model in the lower Antarctic stratosphere appears not only in spring, but also during the southern-hemisphere winter months (not shown). Mean temperature differences occur - up to $10 \mathrm{~K}$ too warm at $50 \mathrm{hPa}$ in comparison to the ECMWF analyses - possibly caused by an underestimation of long-wave radiative cooling (Roeckner et al., 1992).

A particular sensitivity test has been performed to study the impact of systematic temperature errors on the model results. An additional multiannual integration has been conducted employing the principle of "anomaly coupling" (Sausen, 1991), a technique which was originally introduced as a flux correction method to avoid the drift of coupled atmosphere-ocean models (Sausen et al., 1988). In the anomaly coupling mode, the chemistry module CHEM receives observed mean climatological temperatures, but the temperature devi- ations from the multiannual mean are those simulated by ECHAM3. An additional constraint ensures that the relative humidity remains identical. The resulting differences concerning mean ozone columns between the sensitivity experiment and the reference model run (discussed in this study) are less than 10\% (Grewe, 1997). This indicates that the temperature error of the model, though certainly of importance, does not lead to a decisive deterioration in the simulated ozone column distribution. From the result of this sensitivity test we decided to continue the investigations with the model version without the anomaly coupling.

\subsection{Interannual variability of ozone column}

Model results of the interannual variability of the ozone column (compared to the average seasonal cycle) are shown in Fig. 3. At mid and high latitudes a distinct variability from year to year is evident in both hemispheres. Very cold and stable polar vortex northern-hemisphere winters with low ozone columns at polar latitudes (e.g. February, March of year 10) are simulated, but also warm winters with a disturbed polar vortex accompanied by enhanced transport of ozonerich air from mid to high northern latitudes (e.g.
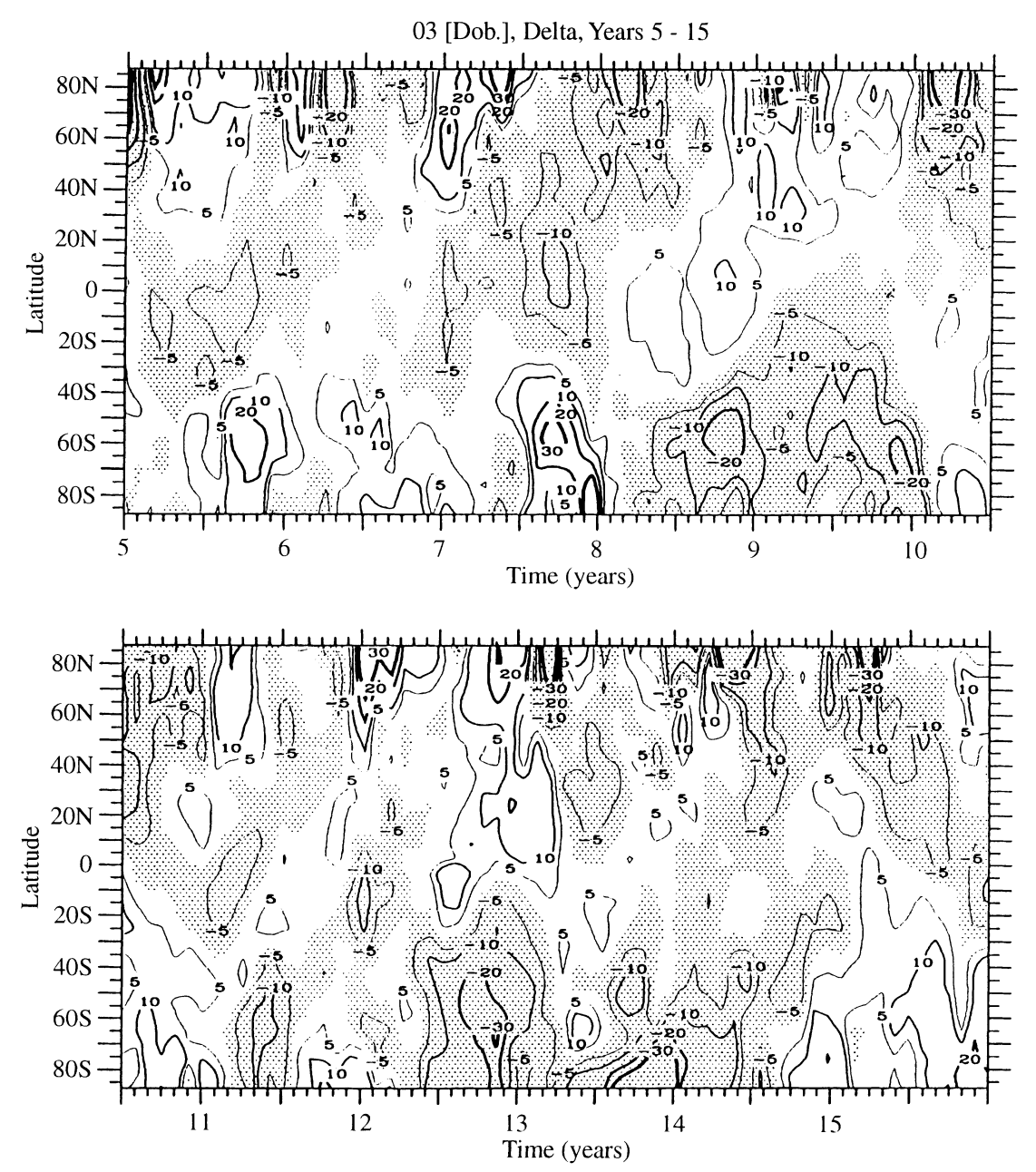

Fig. 3. Latitude-time cross-sections of total ozone deviations of model years 5 to 15 (in DU), from the modelled 11-year mean seasonal cycle (interannual model variability). Dotted areas indicate negative deviations; numbers on the $x$-axis denote the beginning of model year 
January of year 7). The ozone variability in the southern hemisphere is weaker. The calculated depth of the Antarctic ozone hole differs from year to year. Minimum ozone columns below 175 DU (e.g. end October/ beginning November of year 13) are reached. In the tropics, the interannual variability is weak. The results presented in Fig. 3 do not suggest a significant drift of the model due to numerical or other problems. The model gives stable results regarding the ozone distribution, and this holds up for other chemical species as well.

\subsection{Vertical distribution of ozone}

We now turn to the validation of local ozone profiles. Figure 4 shows a comparison of mean profiles at selected ozonesonde stations from the second half of the eighties (Komhyr et al., 1989; Oltmans et al., 1989) and calculated ozone profiles representing the results of model years 5 to 15 at respective model locations (interpolated from surrounded grid points). Although a comparison with point measurements does not do justice to the model resolution, where "grid points" represent boxes of considerable size, some information on the general 3D structure can be gained, in particular as comprehensive long-term 3D observations of ozone do not exist with sufficient global coverage. The model's description of the vertical ozone distribution is qualitatively satisfactory at most altitudes, particularly in the tropics; however, at the mid and high latitudes of both hemispheres the model generally shows ozone values too high compared to observations. Maximum differences are detected in the lower stratosphere at mid-latitudes in winter [i.e. Boulder (DJF), Lauder (JJA)]. Additionally, model deficiencies are evident in describing the vertical ozone distribution near the tropopause. Due to the cold bias of the ECHAM3 model in the polar lower stratosphere, the model tropopause at higher latitudes is found at higher altitudes than observed. The agreement between observed and modelled ozone profiles in the troposphere is good. Our model results regarding tropospheric ozone are also in agreement with results of global tropospheric chemistry simulations discussed by Roelofs and Lelieveld (1995).

\subsection{Importance of PSC chemistry}

A crucial question for the correct performance of the model is the adequate simulation of PSC occurrence by the adopted parameterization. Pawson et al. (1995) estimated the PSC formation potential of the northern hemisphere on the basis of daily temperature analyses for a total of 18 years. They assumed that under certain conditions, type-I PSC formation occurs at temperatures of $195 \mathrm{~K}$ or lower at $50 \mathrm{hPa}$. The time-series of the fractional area of the northern hemisphere (in percent) where the temperature fell below $195 \mathrm{~K}$ is shown in Fig. 5 (dashed curve, from Pawson et al., 1995). The corresponding model result (solid line in Fig. 5) is the 11-year mean of the model-calculated PSC coverages. It is quite consistent that these values are somewhat lower than, but of the same magnitude as the maximum PSC estimates of Pawson et al. (1995). The time-period affected by PSC occurrence is also well reproduced. However, comparison with satellite data by Poole and Pitts (1994) for both hemispheres shows that due to temperature biases in the model, the PSC probability is underestimated near $19 \mathrm{~km}$ and somewhat overestimated at the upper model layers.

The impact on the stratospheric ozone distribution due to heterogeneous reactions on PSCs has been investigated for individual northern-hemisphere winter situations. For this purpose, single winter episodes (December to April) have also been integrated excluding heterogeneous reactions on PSCs. Differences in the concentrations of chemical species between the model runs with (CNTL) and without (HOM) heterogeneous reactions on PSCs are only due to the influence of heterogeneous processes, since the meteorology is identical for both sets of experiments. One example is given in Fig. 6; part a shows the temporal development of various trace gases inside the polar vortex at $50 \mathrm{hPa}$ during one winter. The edge of the polar vortex has been represented by a potential vorticity $(\mathrm{PV})$ value of 35 PVU $\left(=35 \times 10^{-6} \frac{\mathrm{K} \mathrm{m}^{2}}{\mathrm{~kg} \mathrm{~s}^{2}}\right)$ on the $510-\mathrm{K}$ isentrope. Inside the polar vortex, mean ozone mixing ratios of 3.83 ppmv are found, with higher values in December and lower values from February on. A strong denitrification is observed. The chlorine activation $\left(\mathrm{ClO}_{x}\right)$ peaks in late January and early February with more than 1 ppbv. Later active chlorine compounds are first converted into $\mathrm{ClONO}_{2}$ and subsequently into $\mathrm{HCl}$. This successive recombination of active chlorine compounds into the reservoir species $\mathrm{ClONO}_{2}$ and $\mathrm{HCl}$ agrees well with measurements and model calculations (Webster et al., 1993; Douglass et al., 1995; Santee et al., 1996). The influence of PSC surface heterogeneous reactions on the trace gases at $50 \mathrm{hPa}$ is presented in Fig. 6b, which shows the differences between the results of the CNTL and HOM runs. It indicates that chlorine activation, recombination to the reservoir gases $\mathrm{ClONO}_{2}$ and $\mathrm{HCl}$ and the largest part of the denitrification inside the polar vortex result from heterogeneous reactions on PSCs and subsequent sedimentation of NAT particles (see the preceding). Nevertheless, the mixing ratio of $\mathrm{HNO}_{3}$ is too low (2-3 ppbv) for dynamic reasons which will be discussed later in this paper. An ozone reduction of 300 ppbv occurs inside the polar vortex at $50 \mathrm{hPa}$, i.e. $8 \%$ compared to the run, which neglects heterogeneous reactions on PSCs (see also Grewe, 1997).

\subsection{Validation with HALOE data}

The validation of processes can be attempted through comparison with measurements by the Halogen Occultation Experiment (HALOE; for details see J. Geophys. Res., special issue, April 30, 1996, and Russell et al., 1993). Profile measurements by HALOE are obtained at sunset and sunrise. HALOE data of several orbits at consecutive days can be combined at particular pressure 

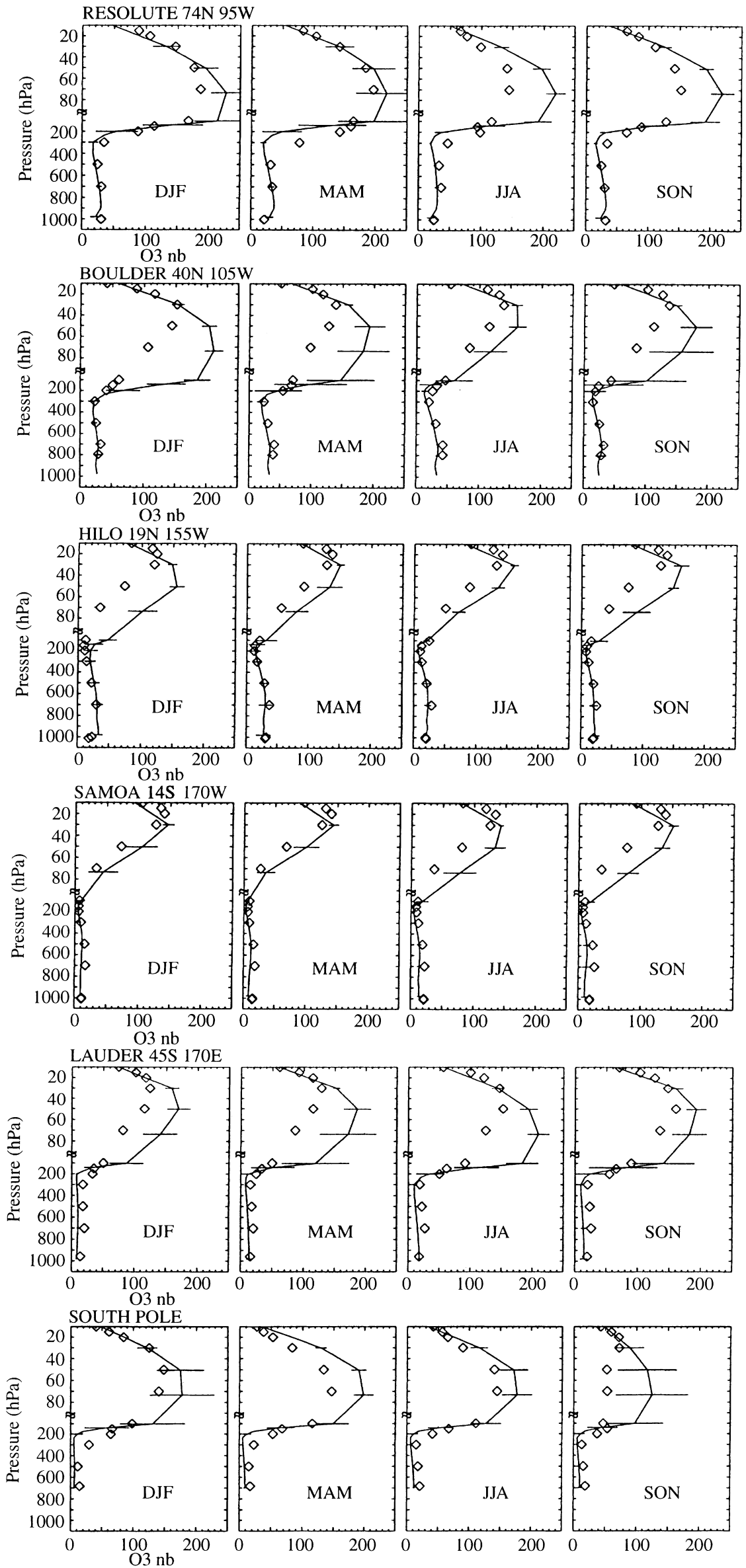

Fig. 4. Intercomparison of measured and simulated mean ozone profiles at different locations: measurements represent the mean state during the second half of the eighties; simulations represent the results of model years $5-15$ at corresponding grid points (see text). Diamonds indicate data based on observations, horizontal bars the $2 \sigma$ variability of model output. Time-averages are for the four seasons DJF, MAM, JJA and SON, respectively; units are in nb 


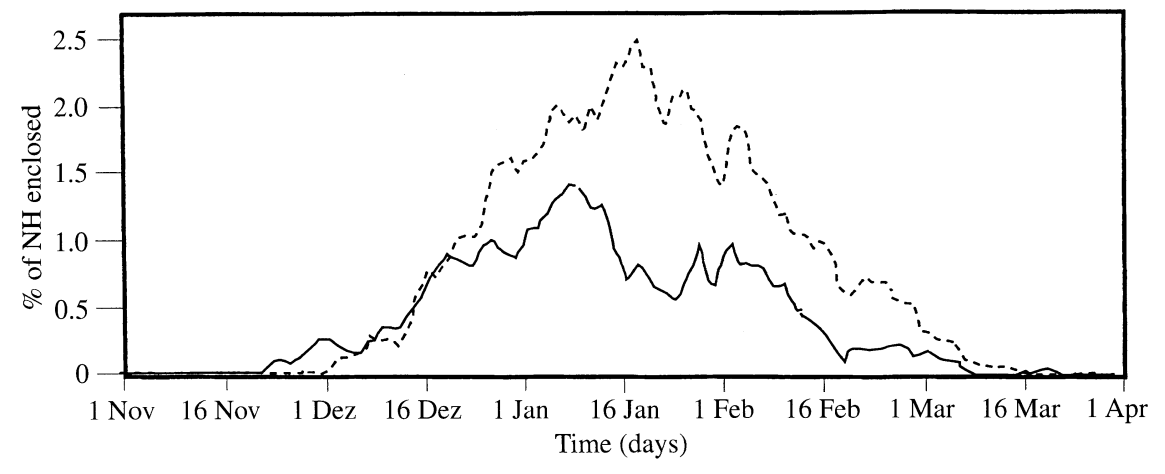

Fig. 5. Solid line: time-series of the fractional area of the northern hemisphere at $50 \mathrm{hPa}$ (in percent) in the model, which is covered by type-I PSC, as calculated by means of the 11year model simulation. Dashed line: timeseries of the fractional area of the northern hemisphere at $50 \mathrm{hPa}$ (in percent) with temperature values below $195 \mathrm{~K}$, as determined by observed temperatures over an 18-year period [reproduced from Pawson et al. (1995)]
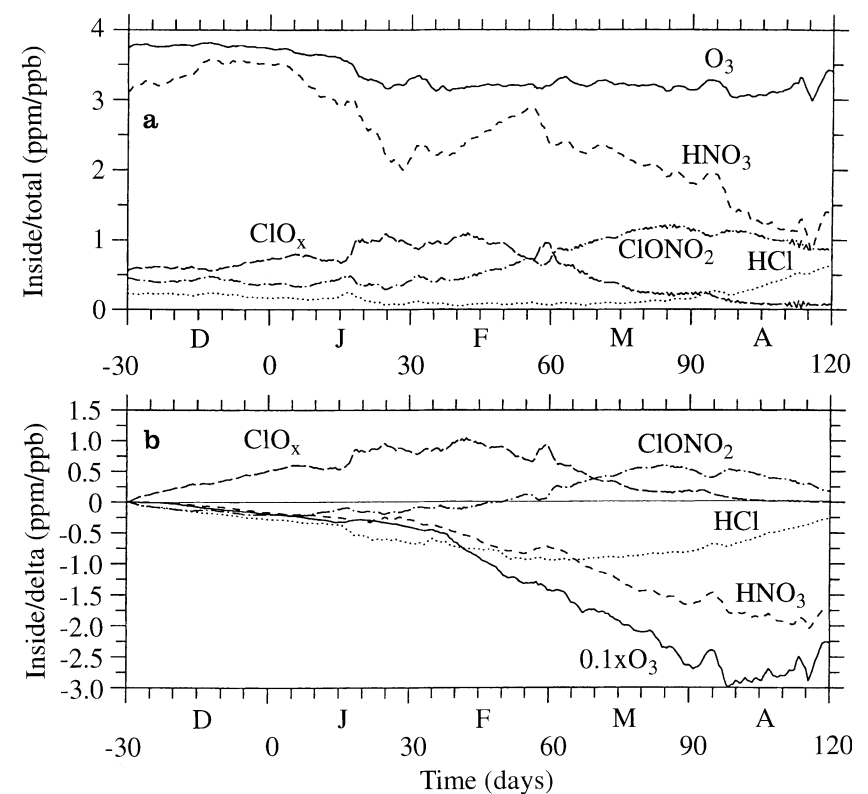

Fig. 6 a Temporal development of the mean mixing ratios of various trace gases at $50 \mathrm{hPa}$ during a northern-hemisphere model winter inside the polar vortex (experiment CNTL); $\mathbf{b}$ influence of heterogeneous reactions on PSCs inside the polar vortex (differences of experiments - (CNTL-HOM)). The units are ppbv, except for $\mathrm{O}_{3}$ : ppmv in a and 0.1 ppmv in $\mathrm{b}$

levels to give a global picture. Although a GCMC simulation in the climate mode does not exactly reproduce the thermal and dynamic conditions of a particular date, two episodes of the 15-year ECHAM3/ CHEM simulation have been selected, because of their great similarities to two observed episodes in 1995, regarding the main dynamic features (e.g. structure and location of the polar vortex). These two episodes represent situations of quite different character: a zonally symmetric circulation pattern during the ozone-hole formation in Antarctic spring and a disturbed situation at the end of an Arctic winter.

\subsubsection{Northern-hemisphere condition}

Figure 7 (left-hand side) shows HALOE ozone measurements (in ppmv) in the northern hemisphere for the time-period 20 March to 31 March 1995, at 30, 50 and $70 \mathrm{hPa}$. For comparison, corresponding model results are presented for 25 March of model year 10 (right-hand side). The model period bears a distinct similarity to observations at the end of March 1995: the polar vortex is elongated and shifted towards lower latitudes (over Siberia). Observed temperatures around 25 March 1995 were still significantly below $200 \mathrm{~K}$ inside the polar vortex at 30 and $50 \mathrm{hPa}$ (Naujokat et al., 1995). The model temperatures inside the polar vortex do not differ significantly from observations (not shown). Inside the polar vortex HALOE observed low ozone mixing ratios. The model shows a similar ozone distribution, i.e. an area of reduced ozone inside the polar vortex surrounded by higher ozone values with a pronounced zonal wave number 1 pattern. However, the model overestimates ozone mixing ratios. Since in February 1995 the vortex was more stable and somewhat colder than in February of model year 10, differences between observations and model results in March are probably caused by the different dynamic histories in the two cases.

Next we turn to the question of whether chemical or dynamic processes dominated the modelled ozone distribution in this case. The coupled model system reproduces well important features of atmospheric chemistry. Inside the polar vortex chlorine is highly activated, as indicated in Fig. 8 (top, left) On 20 March a maximum $\mathrm{ClO}_{x}$ value of $1.6 \mathrm{ppbv}$ is found on the $30-\mathrm{hPa}$ surface in the centre of the polar vortex. The corresponding values of $\mathrm{ClONO}_{2}$ (Fig. 8; top, right) show a minimum of 0.6 ppbv. High $\mathrm{ClONO}_{2}$ mixing ratios up to $2.0 \mathrm{ppbv}$ are found near the edge of the polar vortex, which is in good agreement with observations (e.g. Blom et al., 1995). Only 10 days later, on 30 March $\mathrm{ClO}_{x}$ (Fig. 8; bottom, left) is converted mostly into $\mathrm{ClONO}_{2}$ (Fig. 8; bottom, right). This is in agreement with measurements by the MLS instrument on UARS (Santee et al., 1996), who showed that in the northern hemisphere the decrease in $\mathrm{ClO}_{x}$ is balanced by an increase in $\mathrm{ClONO}_{2}$.

An estimation of the impact of chemical processes on the ozone reduction in the model and in HALOE observations has been made by comparing pressurelongitude cross-sections of $\mathrm{O}_{3}, \mathrm{HCl}, \mathrm{CH}_{4}$ and $\mathrm{ClOX}$. Figure 9a shows HALOE measurements on 21 March 1995 at $65.9^{\circ} \mathrm{N}$. Values of $\mathrm{ClOX}$ are indirectly determined from $\mathrm{HF}$ and $\mathrm{HCl} \mathrm{HALOE}$ measurements using a correlation between $\mathrm{HF}$ and $\mathrm{ClX}$ as estimated with the Mainz 2D model (Grooß, 1996). Air masses, which are 

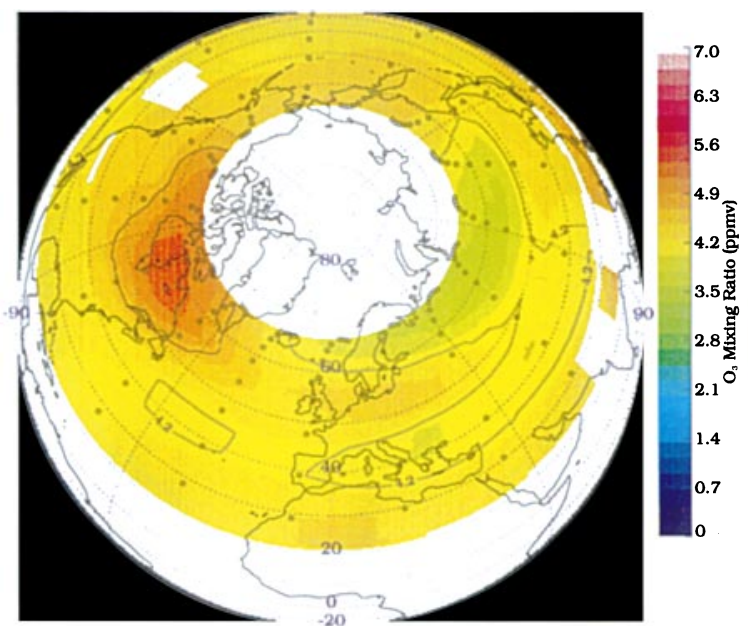

MODEL 03 [ppmv] 30hPa 25. Mar year 10

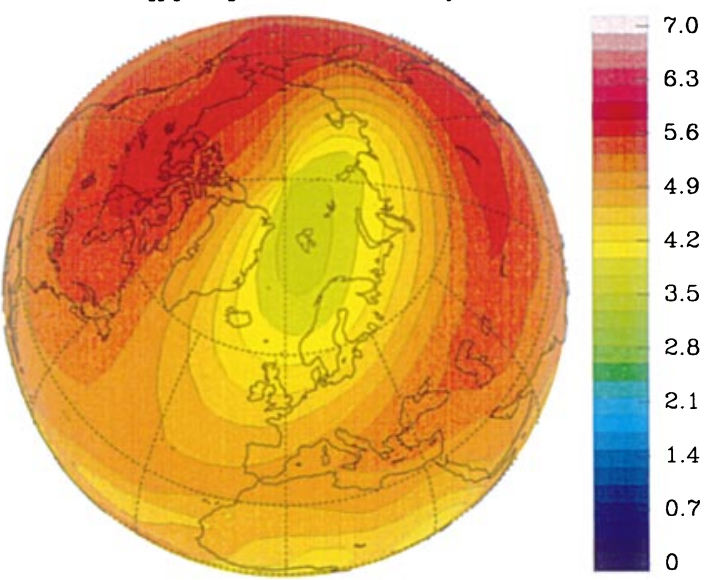

HALOE $\mathrm{O}_{3} 30.00 \mathrm{mb}$ Surface Cross

Section, Sunrise on 20-MAR to 31-MAR-1995

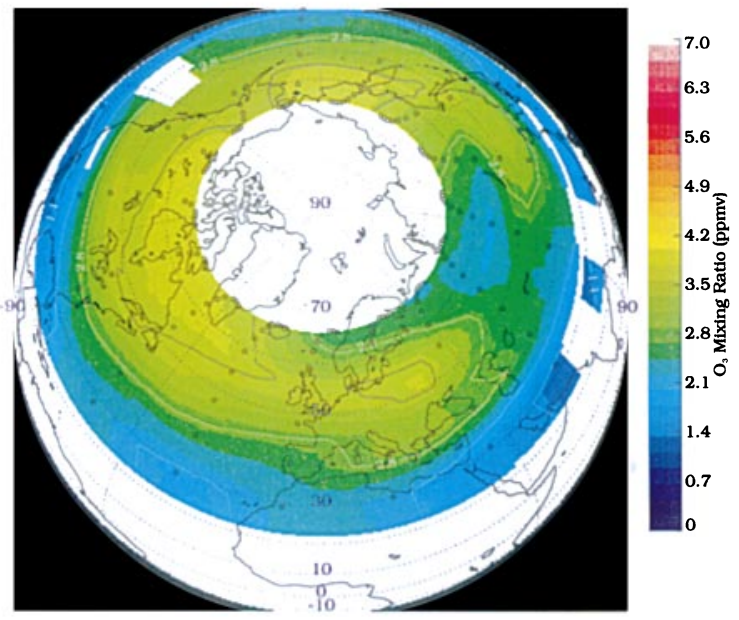

MODEL 03 [ppmv] 50hPa 25. Mar year 10

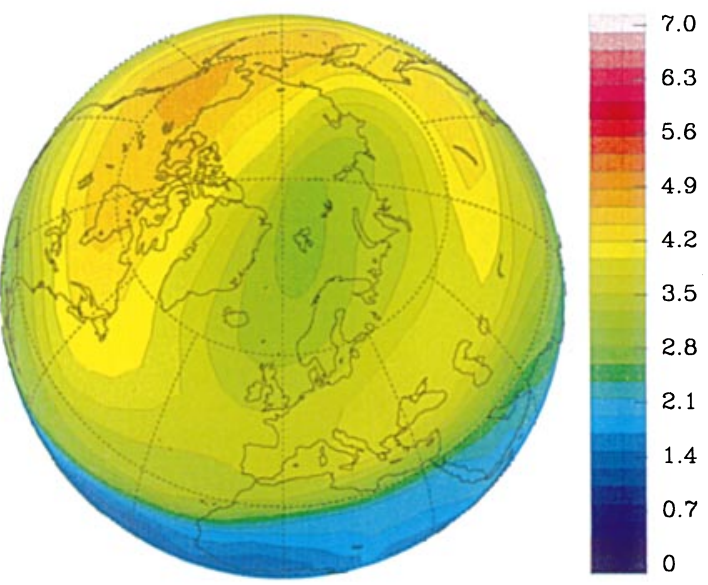

$\mathrm{HALOE} \mathrm{O}_{3} 50.00 \mathrm{mb}$ Surface Cross Section, Sunrise on 20-MAR to 31-MAR-1995
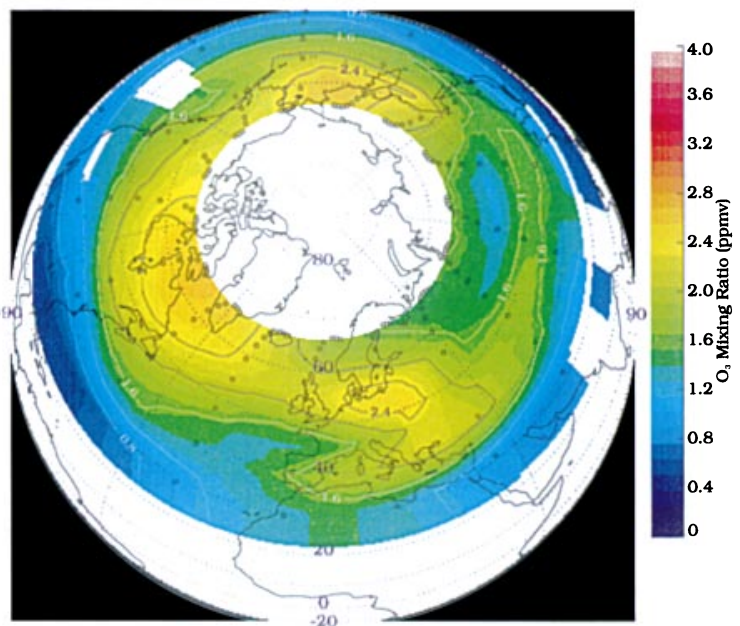

MODEL 03 [ppmv] 70hPa 25. Mar year 10

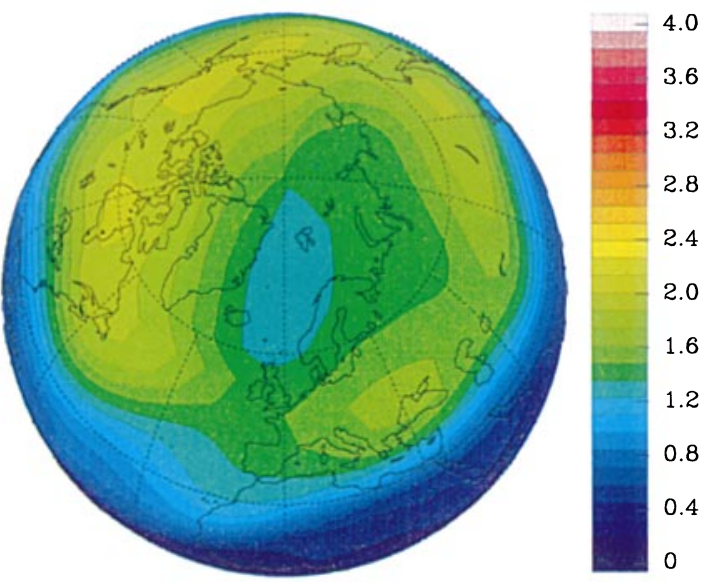

HALOE $\mathrm{O}_{3} 70.00 \mathrm{mb}$ Surface Cross

Section, Sunrise on 20-MAR to 31-MAR-1995

Fig. 7. Left-hand side: northern-hemisphere HALOE ozone measurements (in ppmv) at 30,50 and $70 \mathrm{hPa}$, representing the time-period between 20 and 31 March 1995. Data points (o) progress from high to low latitudes. Right-hand side: corresponding ozone charts from ECHAM3/CHEM on 25 March of model year 10 


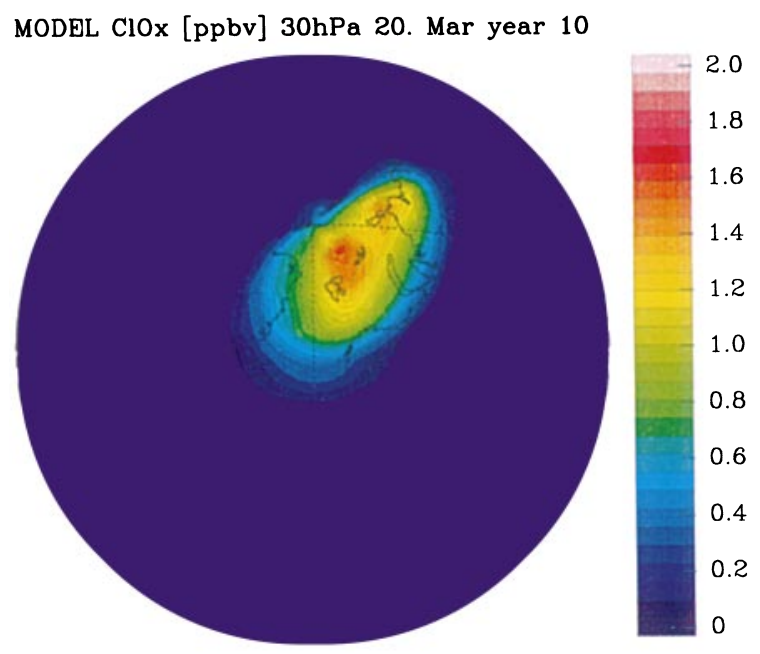

MODEL ClOx [ppbv] 30hPa 30. Mar year 10

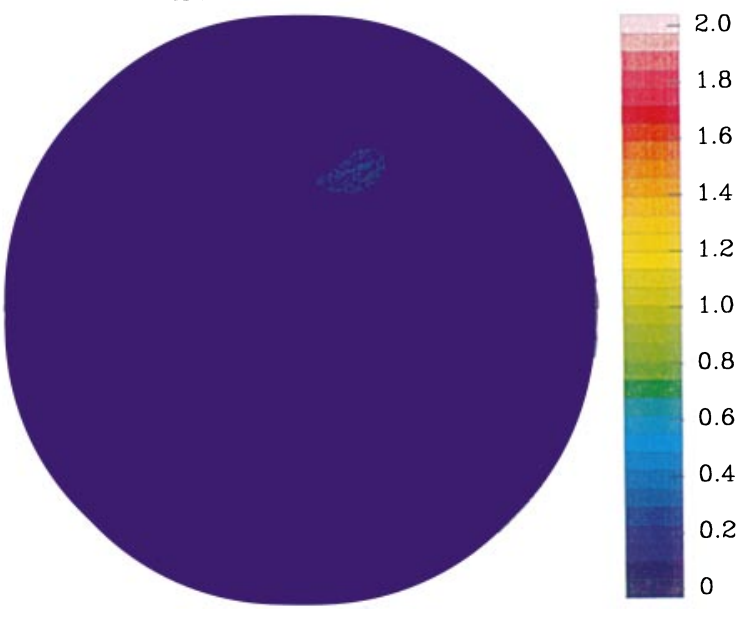

MODEL CIONO2 [ppbv] 30hPa 20. Mar year 10

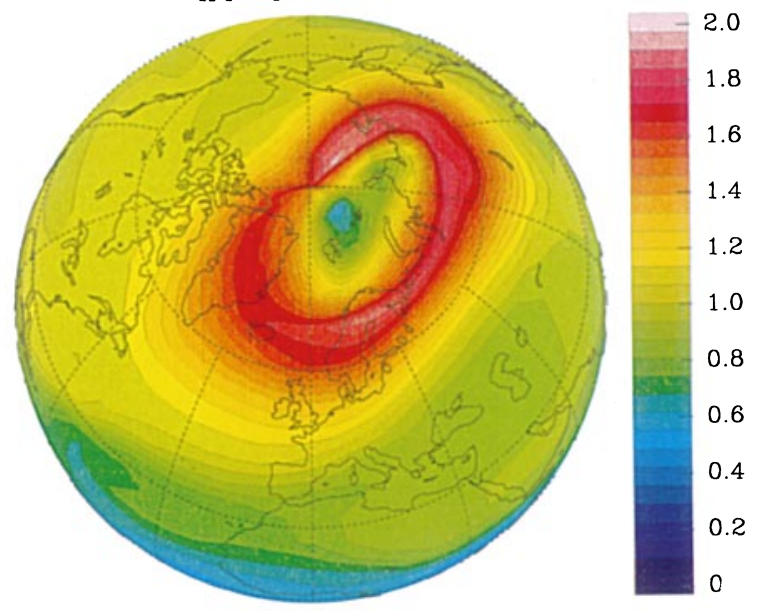

MODEL ClONO2 [ppbv] 30hPa 30. Mar year 10

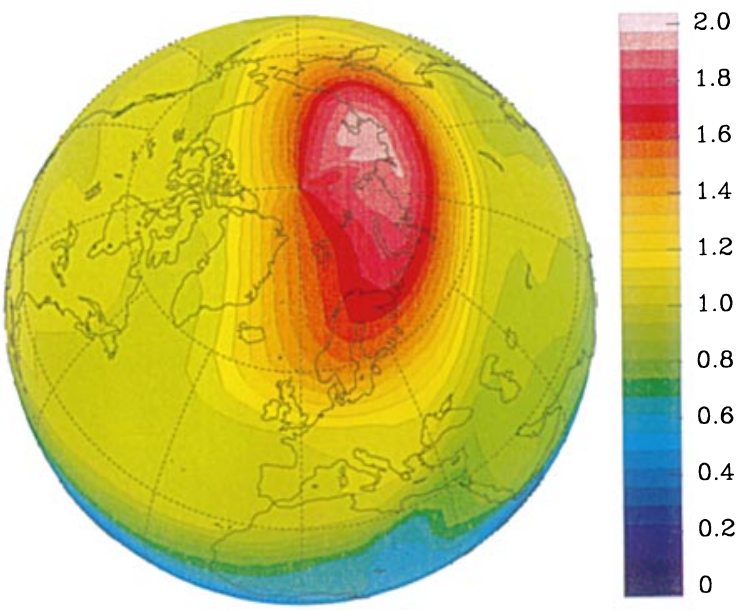

Fig. 8. Northern-hemisphere charts of $\mathrm{ClO}_{x}$ (left-hand side) and of $\mathrm{ClONO}_{2}$ (right-hand side) at $30 \mathrm{hPa}$ on $20 \mathrm{March}$ (top) and $30 \mathrm{March}$ (bottom) of model year 10 (both in ppbv)

located inside the polar vortex, can be identified by low methane mixing ratios $\left(30^{\circ} \mathrm{W}\right.$ to $60^{\circ} \mathrm{E}$ and $120^{\circ} \mathrm{E}$ and $180^{\circ} \mathrm{W}$, between 10 and $100 \mathrm{hPa}$ ), which originate from the downward motion of air inside the vortex. $\mathrm{ClOX}$ is clearly enhanced in these regions, e.g. between 30 and $80 \mathrm{hPa}$ values up to $2.5 \mathrm{ppbv}$ are observed. Corresponding $\mathrm{HCl}$ values inside the vortex are significantly reduced, especially below $40 \mathrm{hPa}$. Since the $\mathrm{HCl}$ mixing ratios at these heights should be $2.5 \mathrm{ppbv}$ or more, the measurements of $\mathrm{HCl}$ give clear evidence of chlorine activation. Considering Fig. 9a, the impact of chemical processes on ozone destruction can be roughly estimated by an examination of isolines of constant methane mixing ratio. Such an estimate can be made assuming that during winter the ratio of ozone and methane remains constant outside the polar vortex. For example, ozone mixing ratios of $1.2-1.5 \mathrm{ppmv}$ are found at $70 \mathrm{hPa}$ inside the vortex, with corresponding methane values of $0.8-0.9$ ppmv. Outside the vortex the same mixing ratios of methane are seen at $10-15 \mathrm{hPa}$, together with ozone mixing ratios of 5-6 ppmv. This yields an estimation of a chemically induced ozone reduction of more than $50 \%$ at $70 \mathrm{hPa}$, taking into account that inside the vortex there is already less ozone in early winter than outside (Müller et al., 1996).

Figure 9b shows corresponding model results on 20 March of model year 10 at $69^{\circ} \mathrm{N}$. The polar vortex is located between $45^{\circ} \mathrm{W}$ and $135^{\circ} \mathrm{E}$. Inside the vortex, ozone mixing ratios are smaller than outside, while mixing ratios of $\mathrm{ClOX}$ are clearly enhanced to more

Fig. 9. a Pressure (height)-longitude cross-sections of HALOE measurements of $\mathrm{O}_{3}$ (in ppmv), $\mathrm{HCl}$ (in ppbv), $\mathrm{CH}_{4}$ (in ppmv) and $\mathrm{ClOX}$ (in pptv) on 21 March 1995 at $65.9^{\circ} \mathrm{N}$. b Same as a, but for 20 March of model year 10 at $69^{\circ} \mathrm{N}$ 

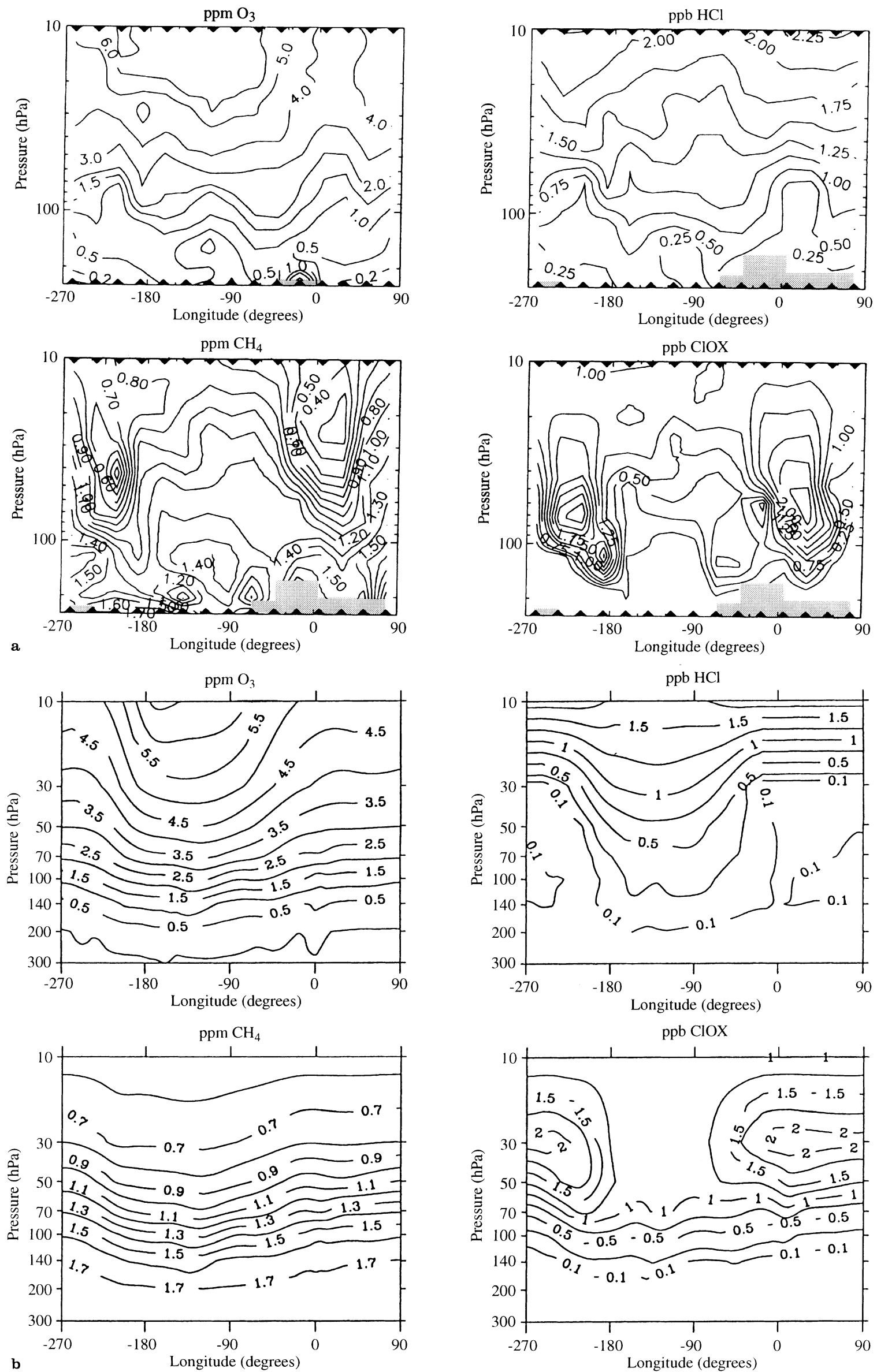

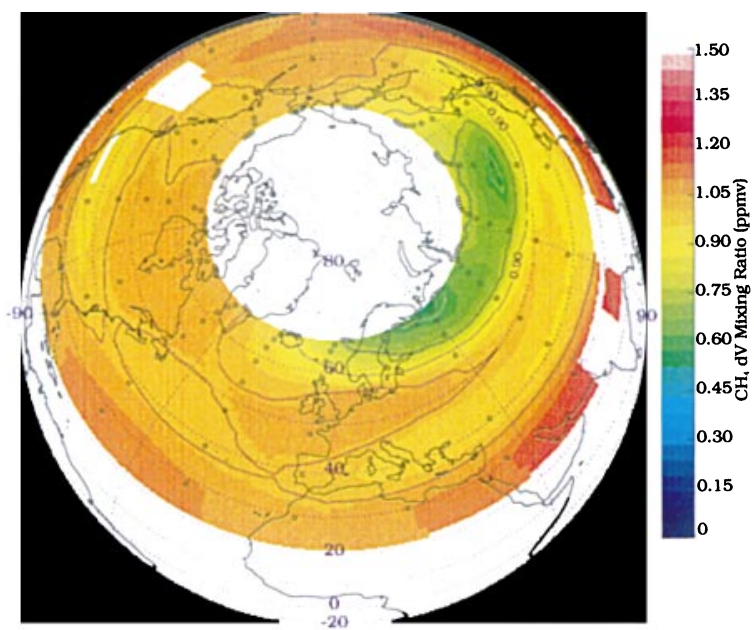

HALOE $\mathrm{CH}_{4} \mathrm{dV} 30.00 \mathrm{mb}$ Surface Cross Section, Sunrise on 20-MAR to 31-MAR-1995

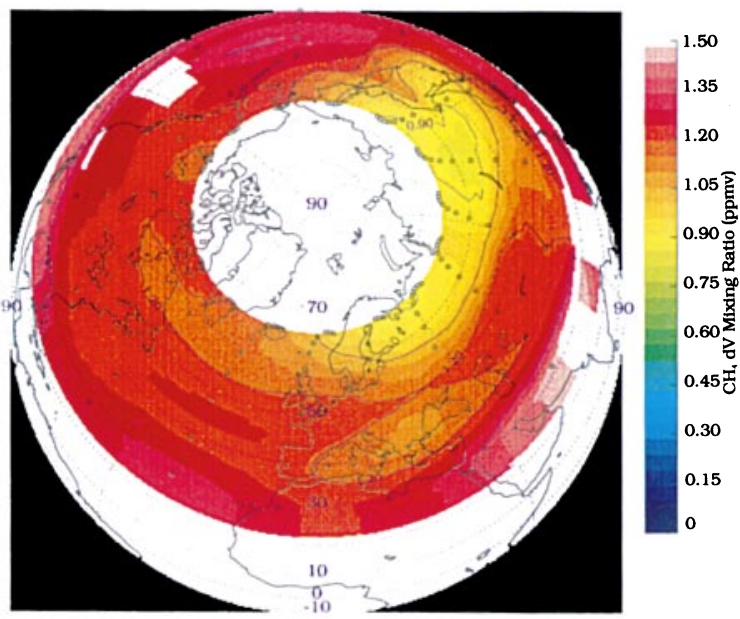

HALOE $\mathrm{CH}_{4} \mathrm{dV} 50.00 \mathrm{mb}$ Surface Cross Section, Sunrise on 20-MAR to 31-MAR-1995

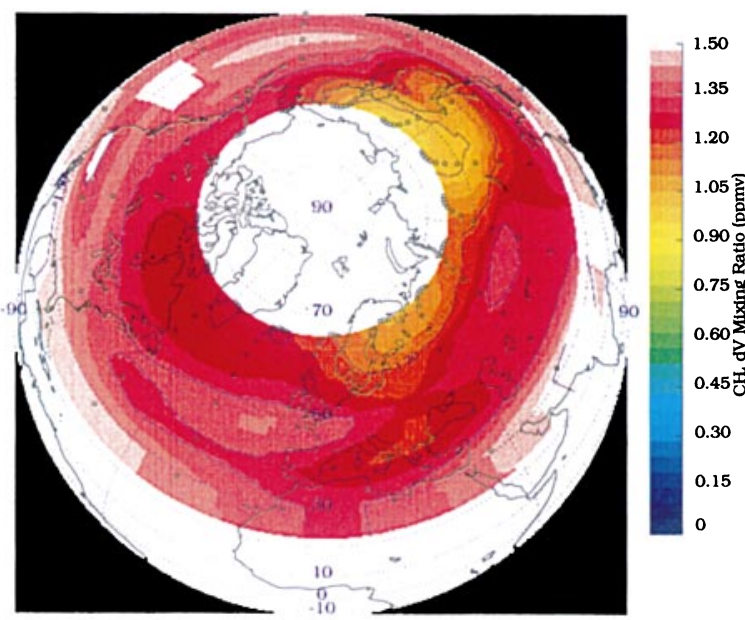

HALOE $\mathrm{CH}_{4} \mathrm{dV} 70.00 \mathrm{mb}$ Surface Cross Section, Sunrise on 20-MAR to 31-MAR-1995
MODEL $\mathrm{CH} 4[\mathrm{ppmv}] 30 \mathrm{hPa} 25 . \mathrm{Mar}$ year 10

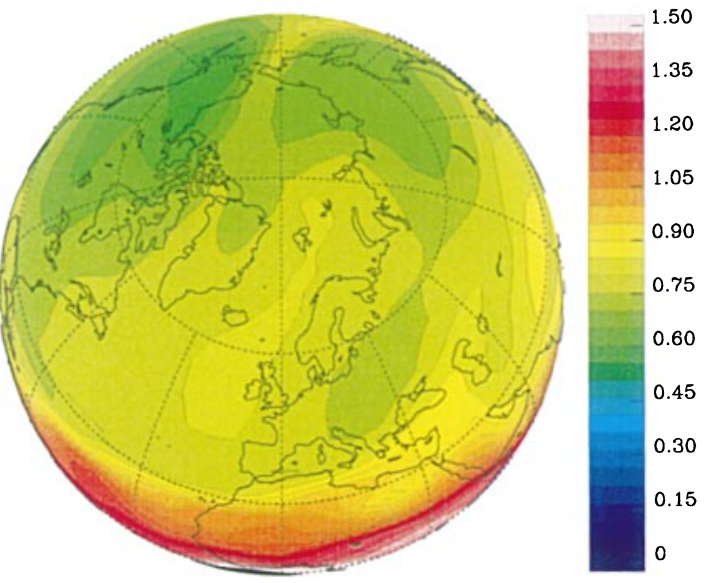

MODEL CH4 [ppmv] $50 \mathrm{hPa} 25$. Mar year 10

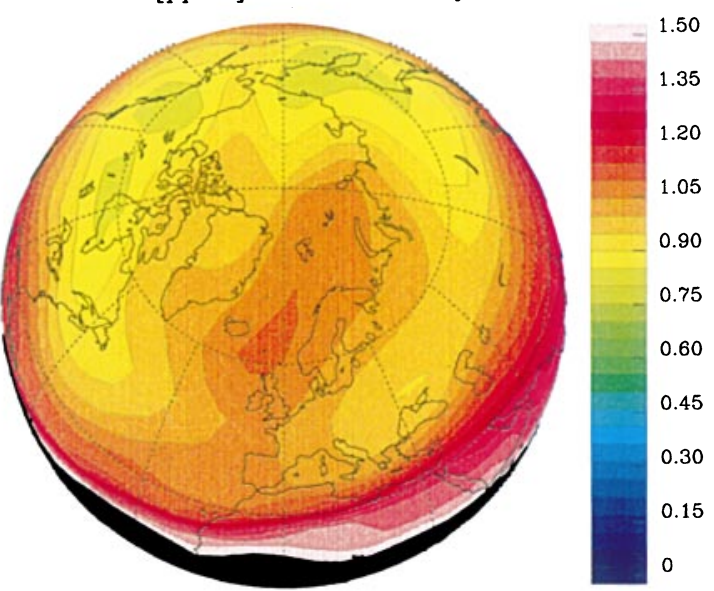

MODEL CH4 [ppmv] 70hPa 25. Mar year 10

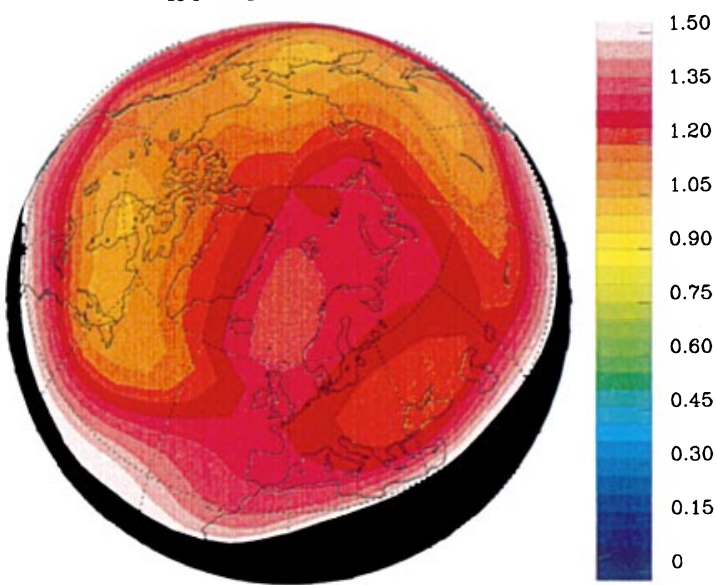

Fig. 10. Same as Fig. 7, but for methane $\left(\mathrm{CH}_{4}\right)$

than 2 ppbv near $30 \mathrm{hPa}$. Here, the agreement with HALOE observations is good. However, below $30 \mathrm{hPa}$ the $\mathrm{ClOX}$ mixing ratios inside the vortex are smaller than observed. The calculated $\mathrm{HCl}$ indicates a more or less complete activation of chlorine inside the polar vortex, suggesting too low values of $\mathrm{ClX}$. 
MODEL $03[\mathrm{ppmv}] 50 \mathrm{hPa} 20$. Mar year 10

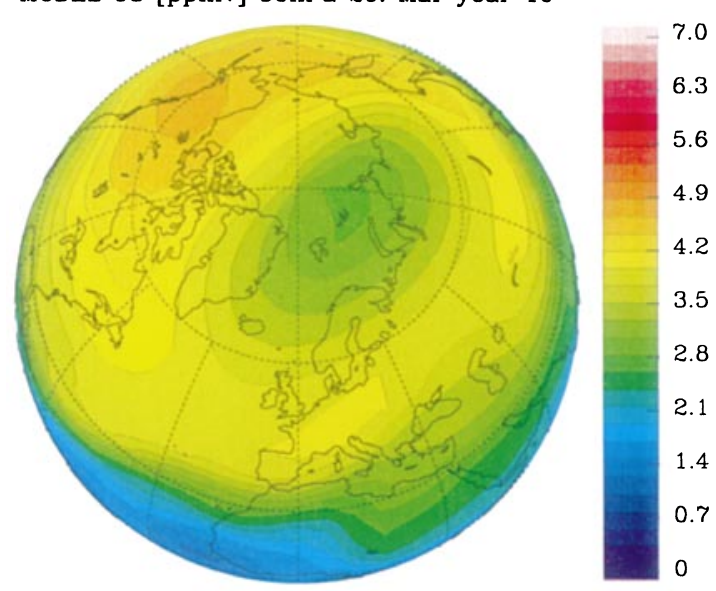

MODEL 03 [ppmv] 50hPa 30. Mar year 10

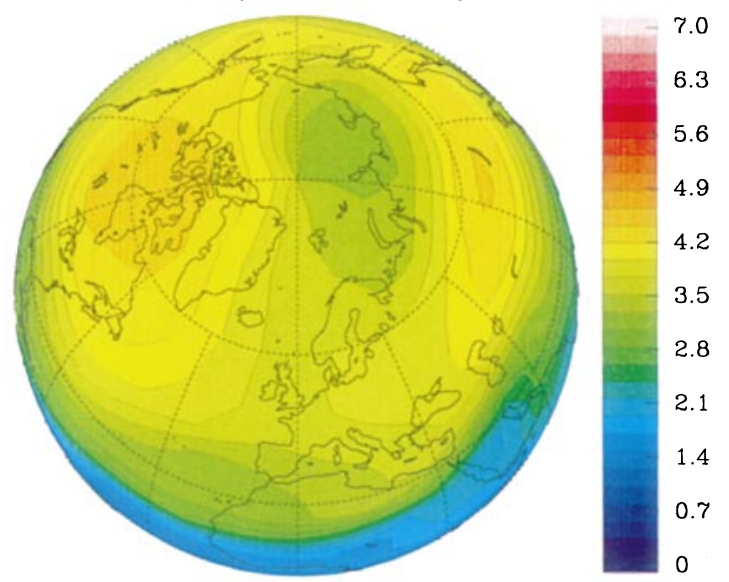

MODEL CH4 [ppmv] 50hPa 20. Mar year 10

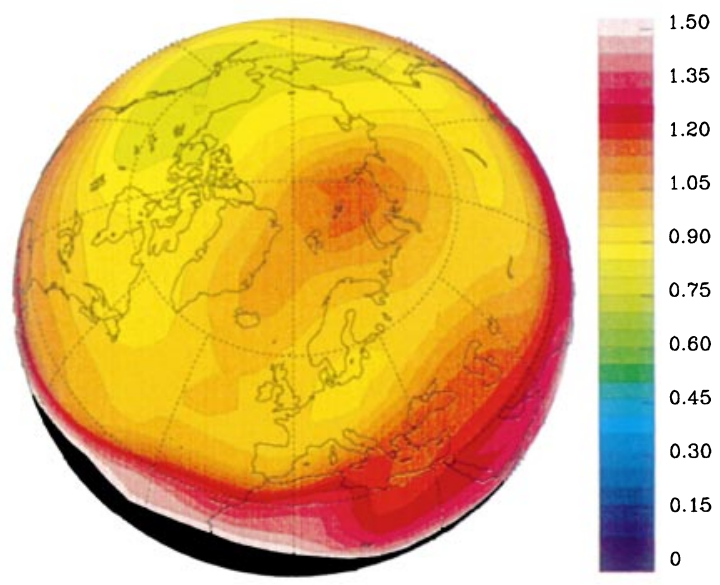

MODEL CH4 [ppmv] 50hPa 30. Mar year 10

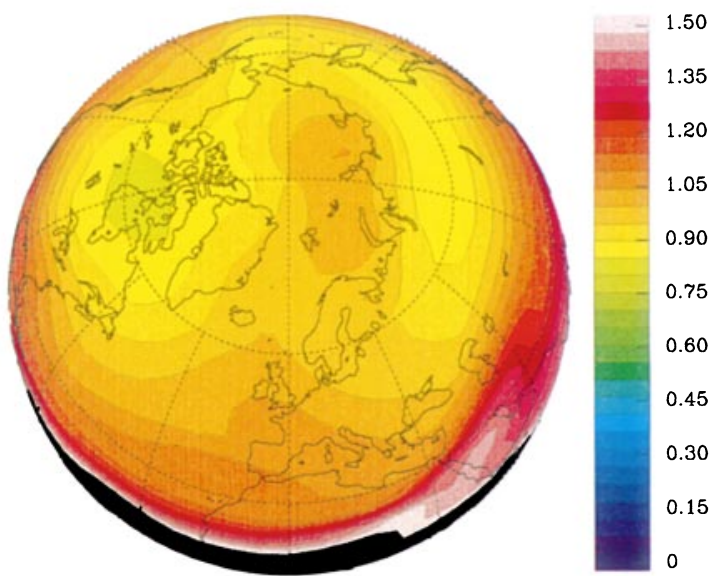

Fig. 11. Northern-hemisphere charts of ozone (left-hand side) and of methane (right-hand side) at $50 \mathrm{hPa}$ on 20 March (top) and $30 \mathrm{March}$ (bottom) of model year 10 (both in ppmv). The corresponding results for 25 March of model year 10 are shown in Figs. 7 and 10 (middle plate)

A significant difference between model results and HALOE observations in the distribution of methane indicates a major shortcoming in model dynamics (Fig. 10). Whereas the HALOE data (left-hand side) indicate a downward movement of air inside the vortex (low $\mathrm{CH}_{4}$ concentration), the model results (right-hand side) show upward transport of air inside the polar vortex (high $\mathrm{CH}_{4}$ concentration). A look at other dynamic tracers supports this finding, in particular calculation of too small values of anorganic total chlorine inside the vortex (Fig. 9b). Therefore, parts of the low ozone values calculated inside the vortex (Fig. 7, right-hand side) are the result of upward transport of ozone-poor air from below (troposphere). Figure 11 shows the temporal development of ozone and methane at the 50-hPa pressure level between 20 March and 30 March of model year 10. It emphasizes the coincidence between regions dominated by upward movement of air and low ozone values. Additionally, Fig. 11 gives an impression of the magnitude of the temporal variability of $\mathrm{O}_{3}$ and $\mathrm{CH}_{4}$ mixing ratios within 10 model days.

The use of the model data for an estimation of the chemically induced ozone reduction inside the polar vortex (Fig. 9b), again based on the examination of isolines of constant $\mathrm{CH}_{4}$ mixing ratios (see above), should lead to significantly smaller ozone reduction. The decreased ozone reduction is caused by the model deficiency concerning vertical transport inside the vortex, leading to less available inorganic chlorine than observed. In agreement, the chemically induced ozone reduction in the model peaks at $30 \mathrm{hPa}$ with $20 \%$ and is smaller at lower heights (approximately $15 \%$ at 50 and $70 \mathrm{hPa}$ ).

\subsubsection{Southern-hemisphere condition}

The model's power to simulate the formation of an Antarctic ozone hole follows from Fig. 1a. Displaying a typical example, Fig. 12 indicates that the ozone hole in the model develops during October. The size of the ozone hole is smaller than expected from observations. It does not cover the whole Antarctic continent, as measurements from the TOMS instrument indicate. Figure 13 (left-hand side) shows the $\mathrm{O}_{3}$ distribution measured by HALOE for the time-period 23 September to 4 October 1995 , at $70 \mathrm{hPa}$. For comparison, the 
MODEL $03[\mathrm{ppmv}] 70 \mathrm{hPa} 05$. Oct year 13

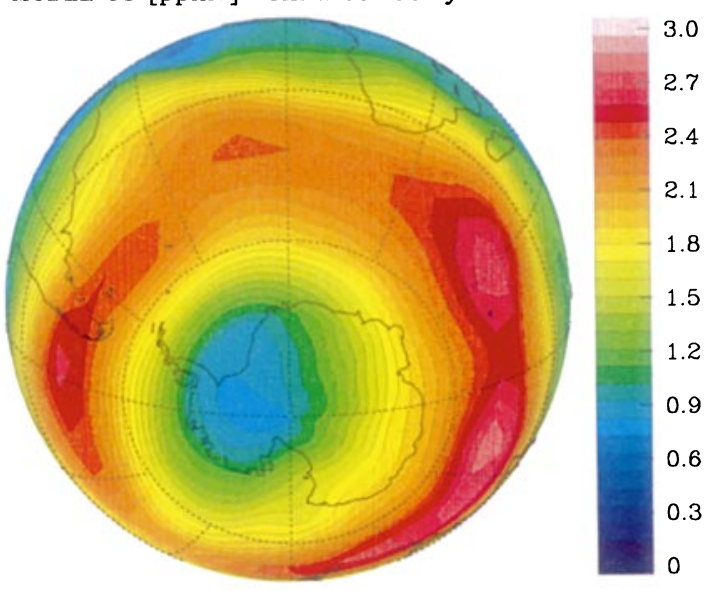

MODEL $03[\mathrm{ppmv}] 70 \mathrm{hPa} 10$. Oct year 13

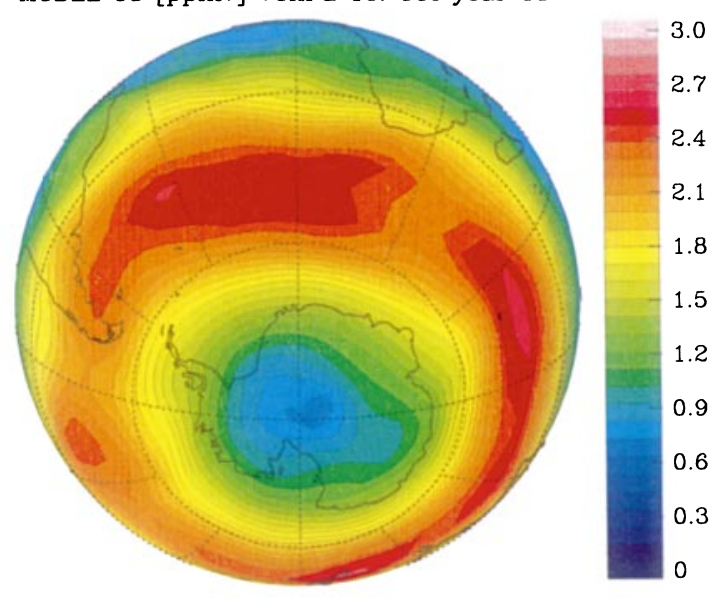

MODEL 03 [ppmv] 7OhPa 15. Oct year 13

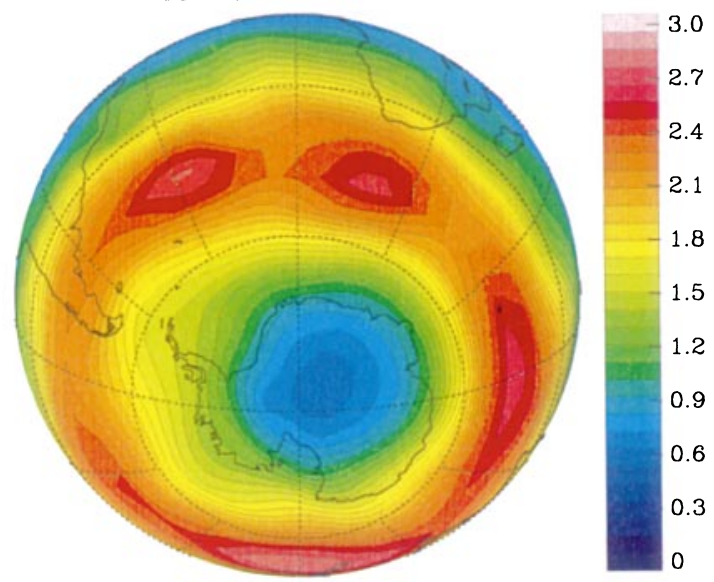

MODEL 03 [ppmv] 70hPa 20. Oct year 13

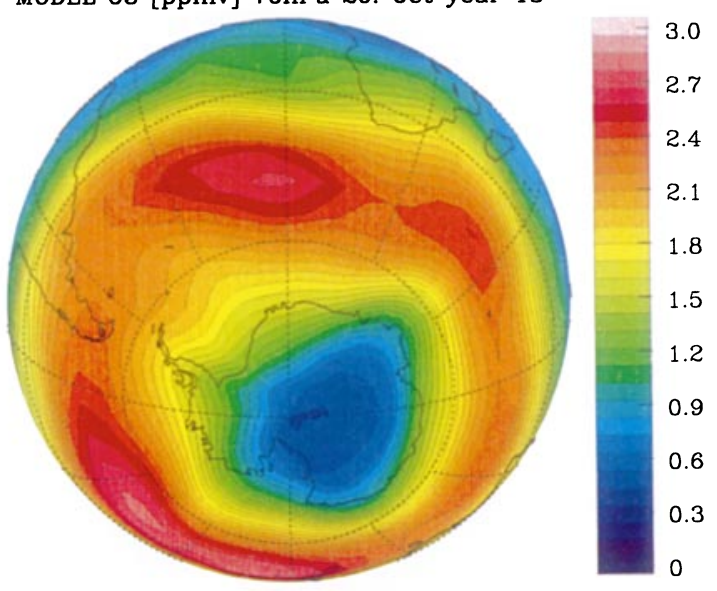

MODEL $03[\mathrm{ppmv}] 70 \mathrm{hPa} 25$. Oct year 13

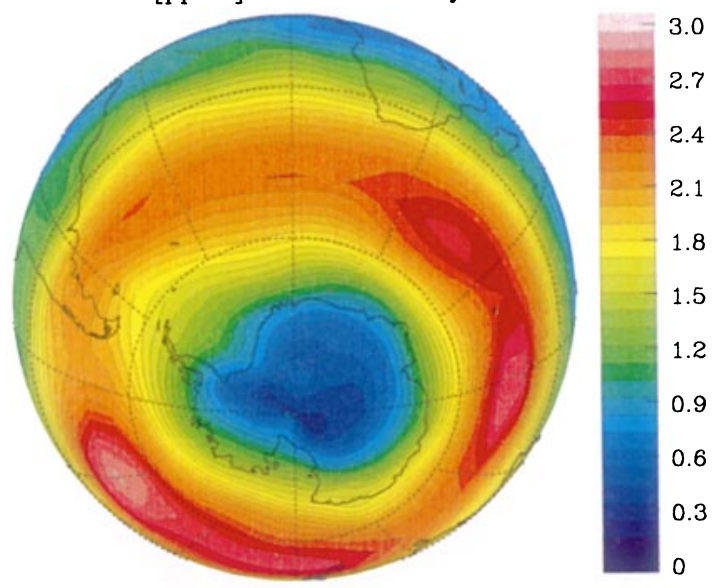

MODEL 03 [ppmv] 70hPa 30. Oct year 13

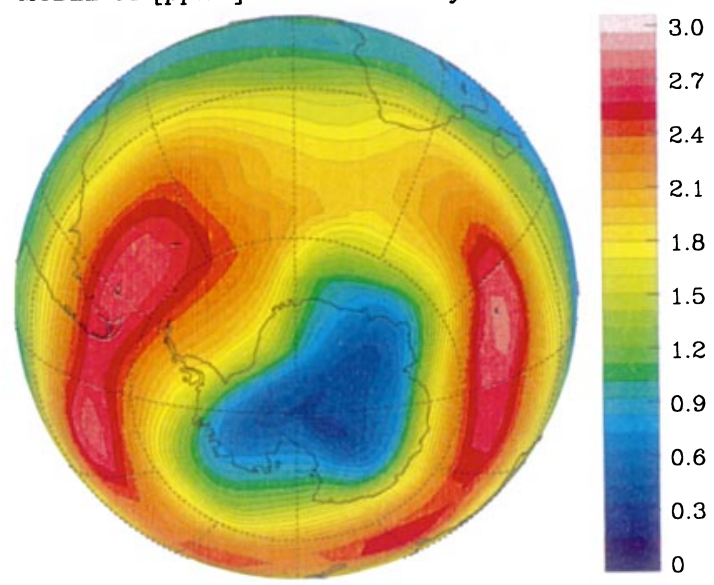

Fig. 12. Temporal development of the Antarctic ozone hole during October for model year 13. Ozone charts (in ppmv) at $70 \mathrm{hPa}$ for 5 to 30 October

corresponding $\mathrm{O}_{3}$ map (right-hand side) on 30 September of model year 13 is shown. At this time the ozone hole is not sufficiently developed in the model (see also Fig. 1a). The model results of the end of October are comparable to the measurements at the beginning of October, indicating that the development of the ozone hole in the model is delayed by approximately 2 weeks. Similar to the case for the northern hemisphere, we 
Section, Sunset on 23-SEP to 04-OCT-1995
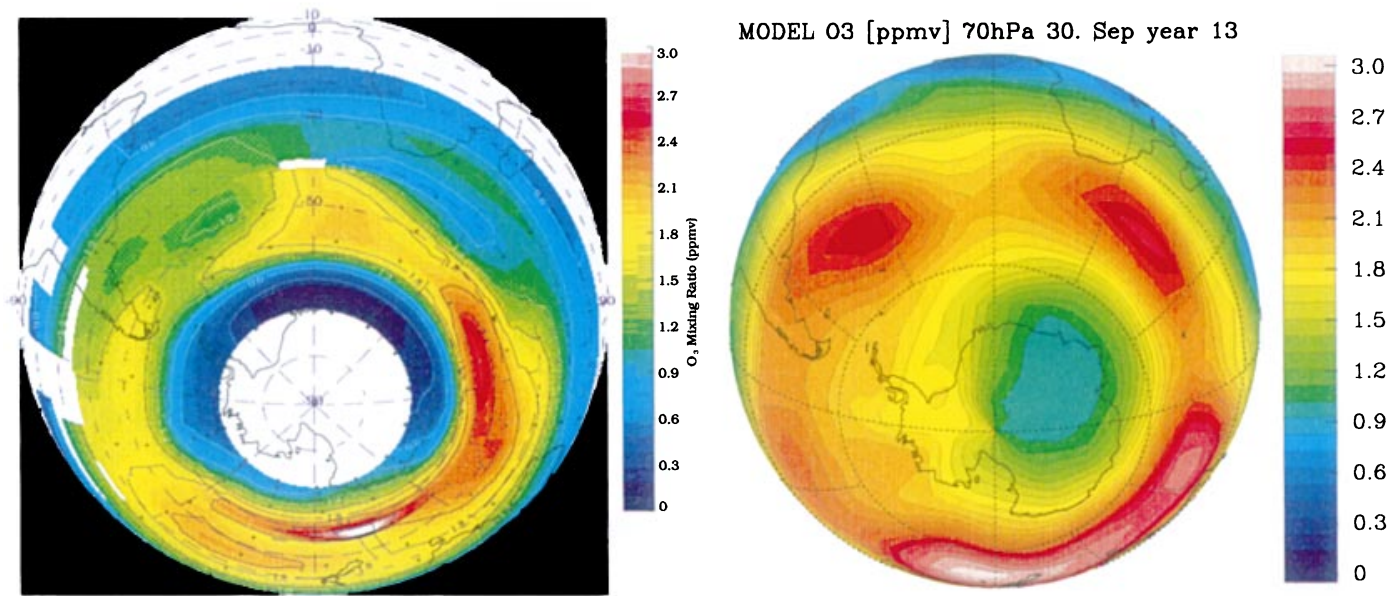

HALOE $\mathrm{O}_{3} 70.00 \mathrm{mb}$ Surface Cross

Section, Sunset on 23-SEP to 04-OCT-1995

Fig. 13. Left-hand side: southern-hemisphere HALOE ozone measurements (in ppmv) at $70 \mathrm{hPa}$, representing the time-period between 23 September and 4 October 1995. Data points $(+)$ progress from low to high latitudes. Right-hand side: corresponding ozone chart of ECHAM3/ CHEM results for 30 September of model year 13

observe a slight upward movement of air near the model top inside the polar vortex, yielding less activated chlorine in the lower stratosphere. At $50 \mathrm{hPa}$ inside the polar vortex, the $\mathrm{ClX}\left(=\mathrm{ClO}_{x}+\mathrm{ClONO}_{2}+\mathrm{HCl}\right)$ model mixing ratios are approximately $1 \mathrm{ppbv}$, significantly smaller than the generally observed values greater than 3 ppbv. Compared to a run with gas phase chemistry only, heterogeneous chemistry locally reduces ozone by up to $30 \%$ between 100 and $30 \mathrm{hPa}$ (see Steil, 1997), which is much less than observed, but consistent with the calculated chlorine. Therefore, low ozone values calculated inside the polar vortex are partly caused by chemical processes, but also by upward transport of ozone-poor air from below.

\subsection{Recovery of chlorine in spring}

The last point we discuss in this section is the model behaviour regarding the recovery of chlorine reservoir species $\mathrm{HCl}$ and $\mathrm{ClONO}_{2}$ during polar spring. For this purpose again, the previously mentioned episodes describing typical northern- and southern-hemisphere conditions are examined.

Hemispheric differences in springtime recovery of the chlorine reservoir gases $\mathrm{ClONO}_{2}$ and $\mathrm{HCl}$ were recently investigated by Douglass et al. (1995) and Grooß et al. (1997). For example, the former's investigation of HALOE observations indicated that in springtime $\mathrm{HCl}$ increases more rapidly in the Antarctic than in the Arctic vortex. Box model calculations showed that this effect is related to the $\mathrm{O}_{3}$ concentrations in the southern winter vortex, which fall far below those in the northern winter vortex. Douglass et al. (1995) also pointed out that as a consequence, the $\mathrm{Cl} / \mathrm{ClO}$ ratio in the southern hemisphere is up to 30 times higher than in the northern hemisphere, leading to much more efficient $\mathrm{HCl}$ formation by the reaction between $\mathrm{Cl}$ and $\mathrm{CH}_{4}$. For a better comparison with northern-hemispheric conditions, where less denitrification is observed, Douglass et al. restricted their analysis to regions near the edge of the polar vortex. There, ozone mixing ratios of approximately $0.5 \mathrm{ppmv}$ are found, close to the values found in our model results inside the polar vortex.

Figures 14 and 15 show time-series of $\mathrm{ClONO}_{2}$ and $\mathrm{HCl}$ at $50 \mathrm{hPa}$ on 10,20 and 30 October of model year 13 and on 30 March and 15 and 30 April of model year 10 for the southern and northern hemispheres, respectively. The quicker recovery of $\mathrm{HCl}$ in the Antarctic region is reproduced quite well (Fig. 14, right-hand side). The last PSC event in the southern hemisphere is observed on 20 October. Following the ozone concentration, the recovery of $\mathrm{HCl}$ ensues within 10 days inside the polar vortex and within 20 days near the vortex edge. While $\mathrm{HCl}$ recovers, $\mathrm{ClONO}_{2}$ decreases. Due to the problems of vertical transport already mentioned, the absolute values of $\mathrm{HCl}$ are, however, approximately three times smaller than observed.

The situation during north polar spring for model year 10 is shown in Fig. 15. Here, PSC formation ends at the end of March, except for a small event between 10 and 15 April. As in the southern hemisphere, the rate of recovery of $\mathrm{HCl}$ is reproduced fairly well. In contrast to south polar spring conditions, during the break up of the polar vortex $\mathrm{HCl}$ and $\mathrm{ClONO}_{2}$ are approximately present in a ratio of 1 to 1 .

\section{Concluding remarks and outlook}

In this study, results of a first multiannual integration with the coupled dynamic-chemical general circulation model ECHAM3/CHEM have been presented. The 
MODEL CIONO2 [ppbv] $50 \mathrm{hPa} 10$. Oct year 13

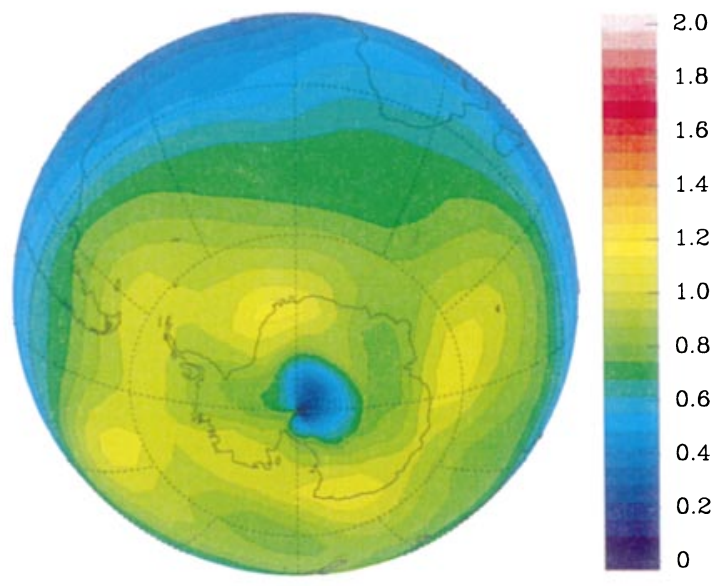

MODEL CIONO2 [ppbv] $50 \mathrm{hPa} 20$. Oct year 13

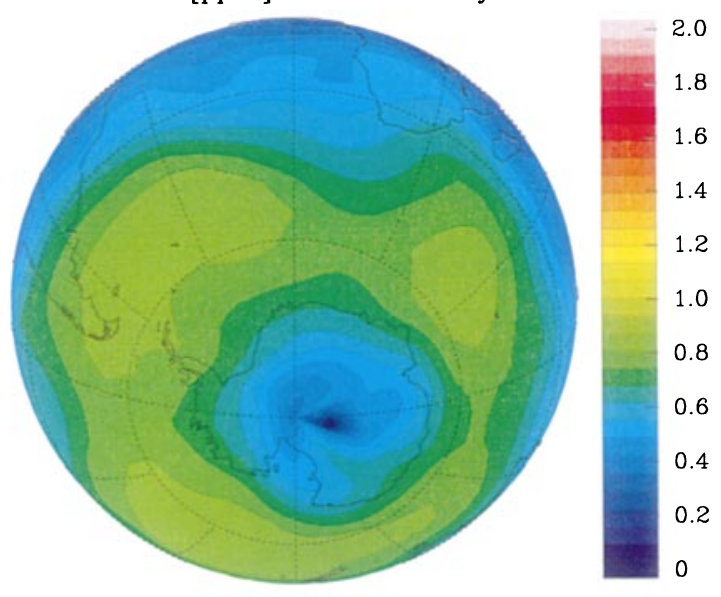

MODEL CIONO2 [ppbv] 50hPa 30. Oct year 13

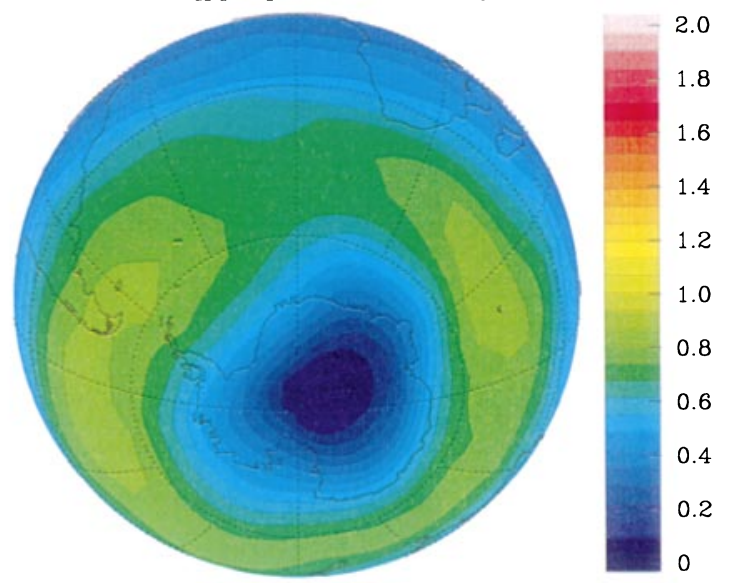

MODEL $\mathrm{HCl}[\mathrm{ppbv}] 50 \mathrm{hPa} 10$. Oct year 13

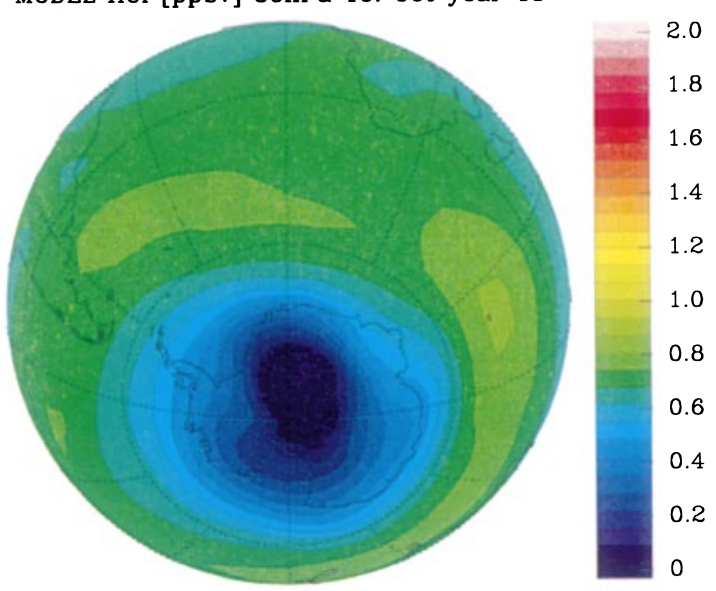

MODEL $\mathrm{HCl}[\mathrm{ppbv}] 50 \mathrm{hPa} 20$. Oct year 13

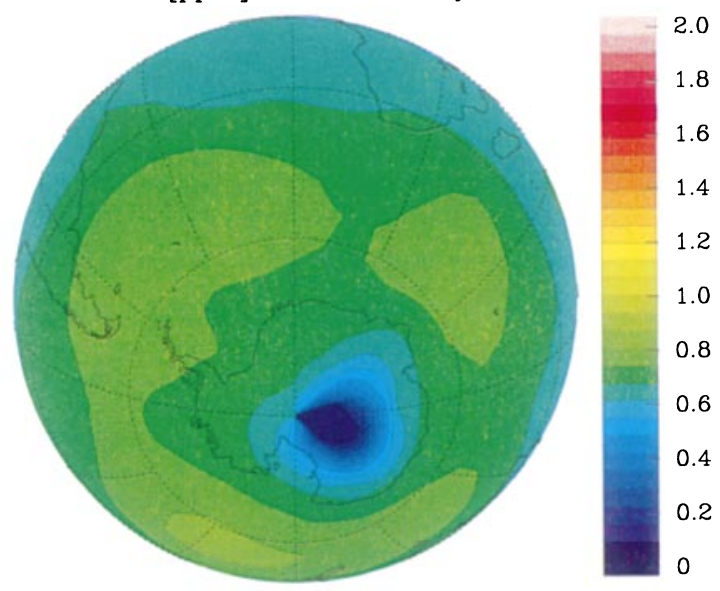

MODEL HCl [ppbv] $50 \mathrm{hPa} 30$. Oct year 13

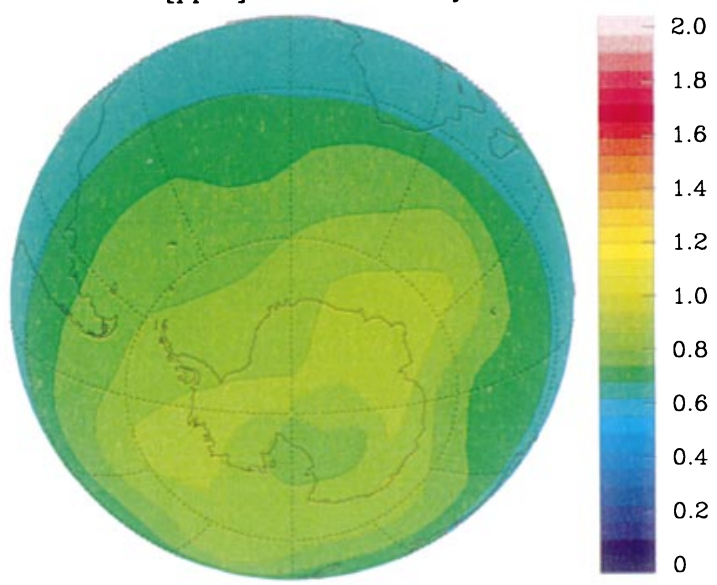

Fig. 14. Southern-hemisphere charts of $\mathrm{ClONO}_{2}$ (left-hand side) and $\mathrm{HCl}$ (right-hand side) for 10, 20 and 30 October of model year 13 at $50 \mathrm{hPa}$. Units are in ppbv

chemical part of the coupled model has been developed to such a high numerical efficiency that integrations over several years are possible. An outstanding result is the stability of the model over this long time-period. No model drift in any dynamic or chemical parameter was detected. Dynamic and chemical processes relevant to the simulated ozone variability are consistently identified. A comparison with observations, particularly 


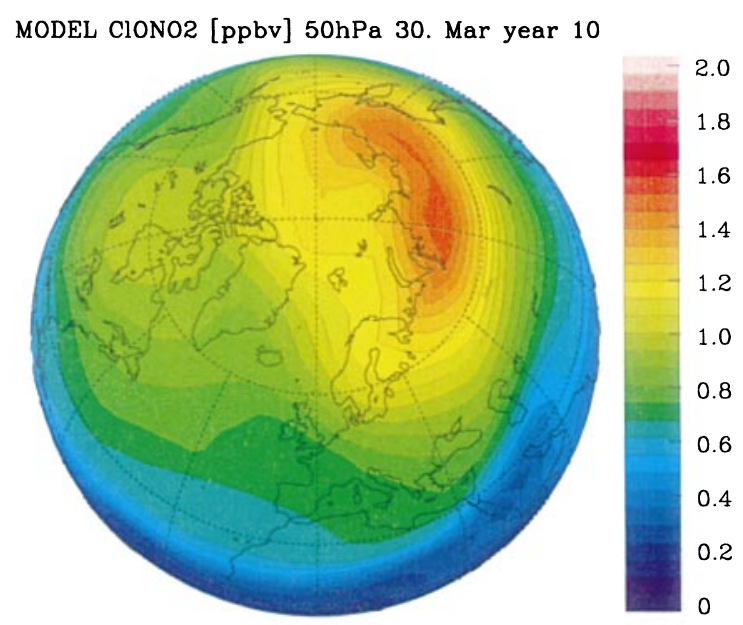

MODEL CIONO2 [ppbv] 5OhPa 15. Apr year 10

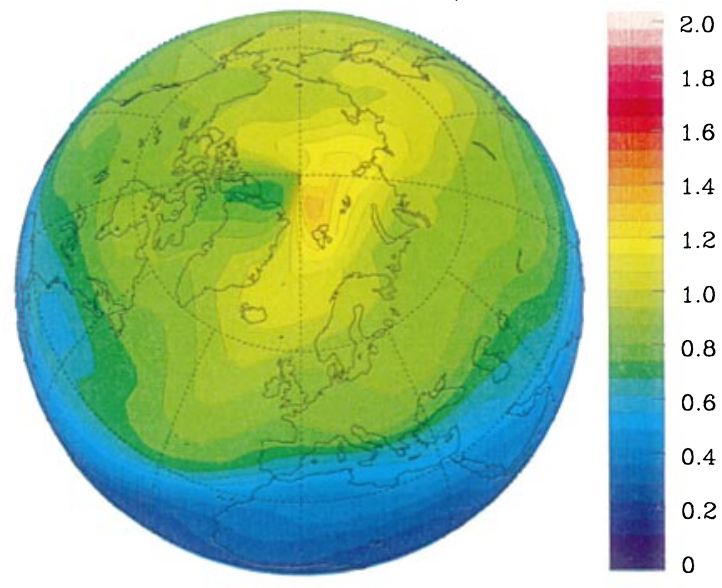

MODEL CIONO2 [ppbv] 50hPa 30. Apr year 10

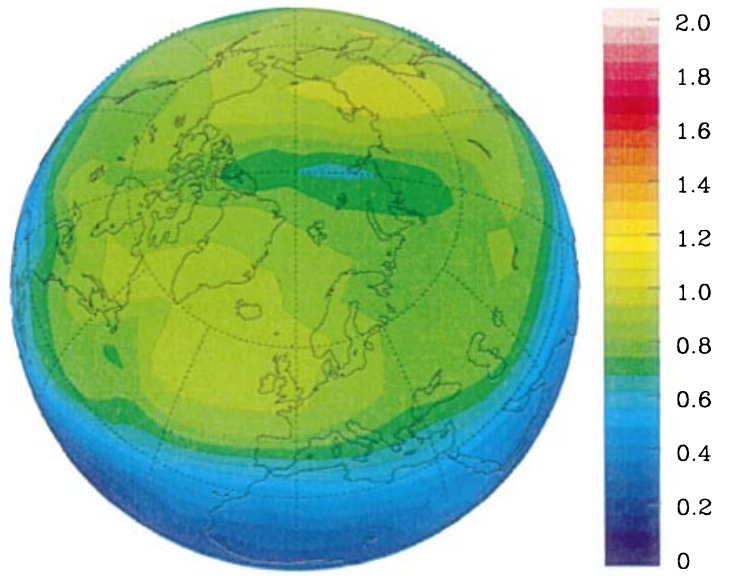

MODEL $\mathrm{HCl}[\mathrm{ppbv}] 50 \mathrm{hPa} 30$. Mar year 10

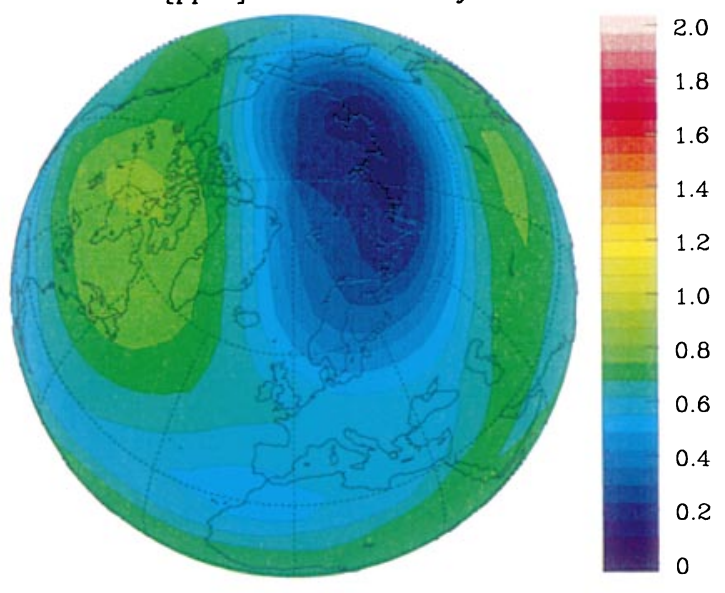

MODEL $\mathrm{HCl}$ [ppbv] 50hPa 15. Apr year 10

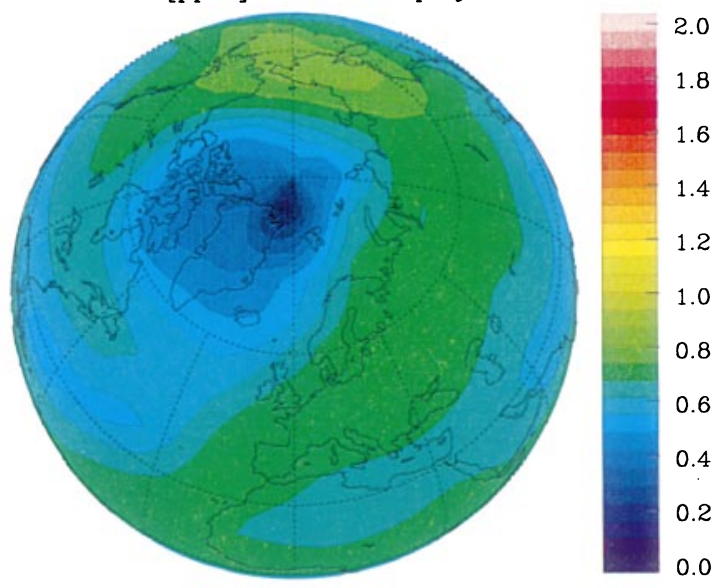

MODEL $\mathrm{HCl}$ [ppbv] 50hPa 30. Apr year 10

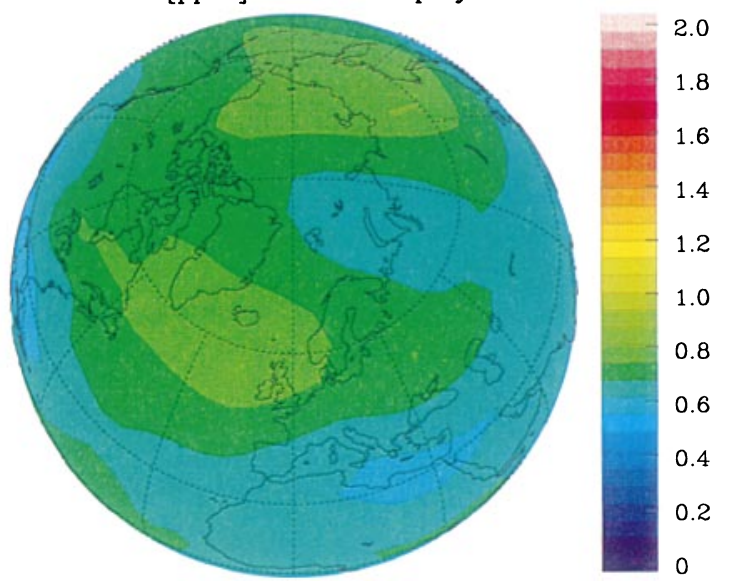

Fig. 15. Northern-hemisphere charts of $\mathrm{ClONO}_{2}$ (left-hand side) and $\mathrm{HCl}$ (right-hand side) for 30 March, 15 and 30 April of model year 10 at $50 \mathrm{hPa}$. Units are in ppbv

HALOE satellite data, indicates strengths and weaknesses of the model with respect to the simulation of the ozone distribution. The main climatological features, i.e. the mean distribution and the intra- and interannual variability, are reproduced. The model describes the vertical ozone distribution qualitatively satisfactorily, even in the troposphere. 
A validation of the model results regarding the fractional area of the northern hemisphere covered with PSCs indicates that the adopted parameterization for the formation and existence of PSCs works quite reasonably. The model is able to reproduce qualitatively the activation of chlorine inside the polar vortices, with stronger activation in the southern than in the northern winter polar vortex. Hemispheric differences regarding the reformation of the chlorine reservoir species $\mathrm{HCl}$ and $\mathrm{ClONO}_{2}$ in spring have also been qualitatively well described by the model.

Deficiencies of the model are mainly due to shortcomings in the dynamic model part: firstly, the tropopause height is overestimated at polar latitudes, allowing for tropospheric ozone-poor air to reach too high altitudes. Secondly, close to the model top a slight upward motion of air is temporarily found inside the polar vortex instead of the observed downward motion. Both model deficits yield an underestimation of the stratospheric chlorine. Considering that ozone destruction depends more than linearly on available chlorine radical concentrations, the simulated Antarctic ozone hole is delayed and is neither as deep nor as large as observed. Additionally, the tendency of the model to produce too stable and longer-lived polar vortices explains some of the differences concerning the horizontal and vertical distribution of ozone both in the southern and northern hemispheres. These problems are a common feature of all GCMs mentioned here.

The main weaknesses of the model concern the dynamics of the stratosphere due to the low vertical resolution in the lower stratosphere and the model top location at $10 \mathrm{hPa}$. A number of shortcomings of the model version reported in this paper are likely to be overcome by use of an upgraded version of the dynamic model part. This version, ECHAM4 (Roeckner, personal communication), will also be made available with a model top at $0.1 \mathrm{hPa}$, which will help to remove the deficiencies in the dynamics of the stratosphere (Manzini and Bengtsson, 1996). Since the vertical resolution of ECHAM3/CHEM must be regarded as insufficient for an adequate capture of cross-tropopause tracer fluxes, a T30/L39 model version (horizontal resolution of about $4.3^{\circ}$; 39 vertical layers between the surface and $10 \mathrm{hPa}$, yielding a vertical resolution near tropopause of approximately $700 \mathrm{~m}$ ) is under development. The chemical package presented in this paper can be used to be coupled to any of these forthcoming models.
ECHAM3/CHEM is an important step towards a comprehensive coupled dynamic-chemical circulation model. Even as it stands, the present configuration forms a solid basis to perform simulations with interactive treatment of dynamics, radiation and chemistry. Test simulations have already been made and will soon be described elsewhere. Considering the results presented here, we firmly expect that in future ECHAM/CHEM can be used for studies of global climate and chemistry changes due to anthropogenic emissions. Prognostic studies, e.g. concerning the impact of aircraft emissions on climate or climatic effects of stratospheric ozone destruction, would appear to be possible in the near future.

Acknowledgements. This study was partly supported by the Bundesministerium für Bildung, Wissenschaft, Forschung und Technologie (BMBF), Bonn, under grants 01 LO 9215, 01 LO 9219 (both Ozonforschungsprogramm), 01 LL 9207/0, 01 LL 9507/4 (both Verbundprogramm "Schadstoffe in der Luftfahrt") and the Deutsche Forschungsgemeinschaft (DFG), Bonn (project: EFSTACK; DFG-Schwerpunktprogramm "Grundlagen der Auswirkungen der Luft- und Raumfahrt auf die Atmosphäre"). We especially thank Drs. E. Roeckner, H. Feichter (both Max-PlanckInstitut für Meteorologie, Hamburg) and Dipl.-Met. U. Schlese (Deutsches Klimarechenzentrum, Hamburg) for helpful discussions and for assistance in running the model. We are also indebted to Dr. G. J. Roelofs (University of Utrecht) who provided the parameterization of tropospheric deposition processes of chemical tracers. We thank the HALOE team at NASA Langley, Hampton, Virginia, for providing the respective data. The ECMWF numerical analyses were used by permission of Deutscher Wetterdienst, Offenbach.

Topical Editor thanks M. P. Chipperfield for his help in evaluating this paper.

\section{Appendix A}

\section{Reactions employed in the model}

Heterogeneous reactions and their reaction probabilities $\gamma$ on sulphuric acid aerosols and PSCs are summarized in Table 1. The $\gamma$-values are recommended by DeMore et al. (1992). The rate constants used in Table 2 are determined following DeMore et al. (1994). Units for the reaction rates are usually [molecules ${ }^{-1} \mathrm{~cm}^{3} \mathrm{~s}^{-1}$ ], with the exception of thermal decay, which is [molecules ${ }^{-1}$ $\left.\mathrm{s}^{-1}\right]$. $T$ denotes temperature in $[K], p$ pressure in $[\mathrm{Pa}]$ and $M$ number of air molecules per $\mathrm{cm}^{3}$.

Table 1. Heterogeneous reactions included in the model $\left[{ }^{a} \gamma\right.$ depends on sulphuric acid content $W$ of the aerosol droplets (and thus is highly temperature dependent) with $\log \gamma=1.86-7.47 \mathrm{~W}$ (Hanson and Ravishankara, 1991) with $W=\max \left(0.25, \sqrt[3]{\frac{\mathrm{T}-188-\left(p \mathrm{H}_{2} \mathrm{O}-5 \times 10^{-4}\right) / 6.9 \times 10^{-5}}{85}}\right)$ and $p \mathrm{H}_{2} \mathrm{O}$ partial pressure of water in $\mathrm{hPa} .{ }^{b}$ The reaction might be of importance for very low temperatures (Cox et al., 1994)]

\begin{tabular}{lllll}
\hline Reaction & & \multicolumn{1}{l}{$\gamma$-value } & & \\
\cline { 3 - 6 } & & NAT & ice & $\mathrm{SO}_{4}^{2-}$ \\
\hline$R_{P 1}$ & $\mathrm{ClONO}_{2}+\mathrm{HCl} \rightarrow \mathrm{Cl}_{2}+\mathrm{HNO}_{3}$ & 0.3 & 0.3 & 0 \\
$R_{P 2}, R_{S 1}$ & $\mathrm{ClONO}_{2}+\mathrm{H}_{2} \mathrm{O} \rightarrow \mathrm{HOCl}+\mathrm{HNO}_{3}$ & 0.006 & 0.3 & $f(\mathrm{~T})^{a}$ \\
$R_{P 3}$ & $\mathrm{HOCl}+\mathrm{HCl} \rightarrow \mathrm{Cl}_{2}+\mathrm{H}_{2} \mathrm{O}$ & 0.1 & 0.3 & $0^{b}$ \\
$R_{P 4}, R_{S 2}$ & $\mathrm{~N}_{2} \mathrm{O}_{5}+\mathrm{H}_{2} \mathrm{O} \rightarrow 2 \mathrm{HNO}_{3}$ & 0.0006 & 0.03 & 0.1 \\
\hline
\end{tabular}


Table 2. Gasphase reactions included in the model

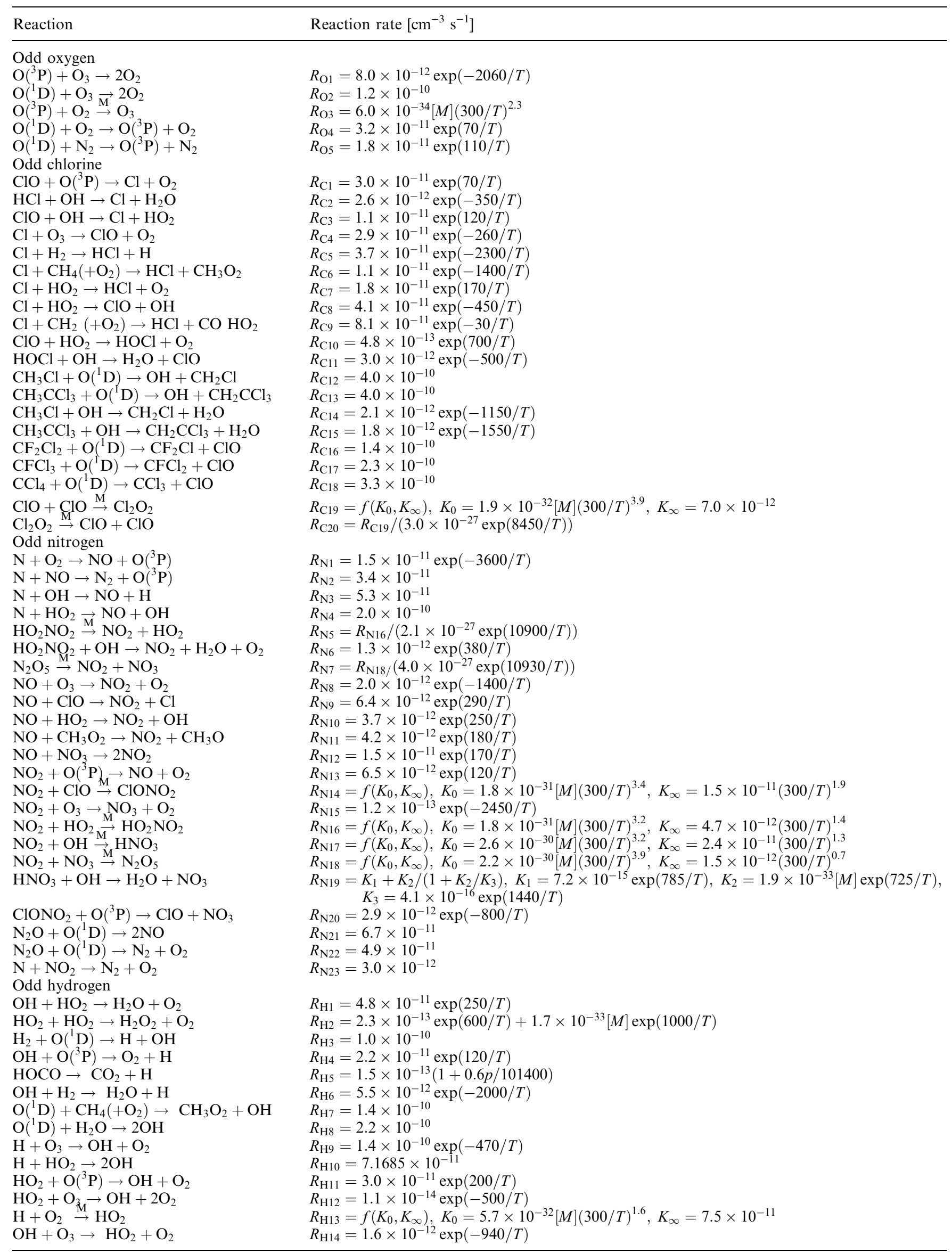


Table 2. (contd)

\begin{tabular}{ll}
\hline Reaction & Reaction rate $\left[\mathrm{cm}^{-3} \mathrm{~s}^{-1}\right]$ \\
\hline $\mathrm{OH}+\mathrm{H}_{2} \mathrm{O}_{2} \rightarrow \mathrm{H}_{2} \mathrm{O}+\mathrm{HO}_{2}$ & $R_{\mathrm{H} 15}=2.9 \times 10^{-12} \exp (-160 / T)$ \\
$\mathrm{OH}+\mathrm{CH}_{2} \mathrm{O}+\mathrm{O}_{2} \rightarrow \mathrm{CO}+\mathrm{HO}_{2}+\mathrm{H}_{2} \mathrm{O}$ & $R_{\mathrm{H} 16}=1.0 \times 10^{-11}$ \\
$\mathrm{H}+\mathrm{HO}_{2} \rightarrow \mathrm{H}_{2}+\mathrm{O}_{2}$ & $R_{\mathrm{H} 17}=6.885 \times 10^{-12}$ \\
$\left.\mathrm{H}+\mathrm{HO}_{2} \rightarrow \mathrm{H}_{2} \mathrm{O}+\mathrm{O}{ }^{3} \mathrm{P}\right)$ & $R_{\mathrm{H} 18}=1.62 \times 10^{-12}$ \\
$\mathrm{OH}+\mathrm{CH}_{4}\left(+\mathrm{O}_{2} \rightarrow \mathrm{CH}_{3} \mathrm{O}_{2}+\mathrm{H}_{2} \mathrm{O}\right.$ & $R_{\mathrm{H} 19}=2.95 \times 10^{-12} \exp (-1815 / T)$ \\
$\mathrm{OH}+\mathrm{CH}_{3} \mathrm{O}_{2} \mathrm{H} \rightarrow \mathrm{CH}_{3} \mathrm{O}_{2}+\mathrm{H} \mathrm{H}_{2} \mathrm{O}$ & $R_{\mathrm{H} 20}=5.9 \times 10^{-12}$ \\
$\mathrm{OH}+\mathrm{CH}_{3} \mathrm{O}_{2} \mathrm{H} \rightarrow \mathrm{CH}_{2} \mathrm{O}+\mathrm{OH}+\mathrm{H}_{2} \mathrm{O}$ & $R_{\mathrm{H} 21}=4.1 \times 10^{-12}$ \\
$\mathrm{HO}_{2}+\mathrm{CH}_{3} \mathrm{O}_{2} \rightarrow \mathrm{CH}_{3} \mathrm{O}_{2} \mathrm{H}+\mathrm{O}_{2}$ & $R_{\mathrm{H} 22}=3.8 \times 10^{-13} \exp (800 / T)$ \\
$\mathrm{O}_{2}+\mathrm{CH}_{3} \mathrm{O} \rightarrow \mathrm{HO}_{2}+\mathrm{CH}_{2} \mathrm{O}$ & $R_{\mathrm{H} 23}=3.9 \times 10^{-14} \exp (-900 / T)$ \\
\hline
\end{tabular}

Termolecular reaction, $f$ from DeMore et al., 1994: $f\left(K_{0}, K_{\infty}\right)=\frac{K_{0}}{1+K_{0} / K_{\infty}} 0.6^{\left(1+\left[\log _{10}\left(K_{0} / K_{\infty}\right)\right]^{2}\right)^{-1}}, K_{0}$ low pressure limit, $K_{\infty}$ high pressure limit

Table 3. Photolytic reactions used in the model

\begin{tabular}{|c|c|c|c|c|}
\hline \multicolumn{4}{|l|}{ Reaction } & \multirow[t]{2}{*}{$\lambda_{\max }[\mathrm{nm}]$} \\
\hline Odd oxygen & & & & \\
\hline $\mathrm{O}_{2}+\mathrm{h} v$ & $\rightarrow$ & $2 \mathrm{O}\left({ }^{3} \mathrm{P}\right)$ & $J_{\mathrm{O}_{2}}$ & 242 \\
\hline $\mathrm{O}_{3}+\mathrm{h} v$ & $\rightarrow$ & $\mathrm{O}\left({ }^{1} \mathrm{D}\right)+\mathrm{O}_{2}$ & $J_{\mathrm{O}\left({ }^{1} \mathrm{D}\right)}$ & 320 \\
\hline $\mathrm{O}_{3}+\mathrm{h} v$ & $\rightarrow$ & $\mathrm{O}\left({ }^{3} \mathrm{P}\right)+\mathrm{O}_{2}$ & $J_{\mathrm{O}\left({ }^{3} \mathrm{P}\right)}$ & 850 \\
\hline $\mathrm{N}_{2} \mathrm{O}+\mathrm{h} v$ & $\rightarrow$ & $\mathrm{N}_{2}+\mathrm{O}\left({ }^{1} \mathrm{D}\right)$ & $J_{\mathrm{N}_{2} \mathrm{O}}$ & 241 \\
\hline $\mathrm{CO}_{2}+\mathrm{h} v$ & $\rightarrow$ & $\mathrm{CO}+\mathrm{O}\left({ }^{3} \mathrm{P}\right)$ & $J_{\mathrm{CO}_{2}}$ & 202 \\
\hline \multicolumn{5}{|l|}{ Odd chlorine } \\
\hline $\mathrm{CH}_{3} \mathrm{Cl}+\mathrm{h} v$ & $\rightarrow$ & $\mathrm{Cl}+$ products & $J_{\mathrm{CH}_{3} \mathrm{Cl}}$ & 222 \\
\hline $\mathrm{CH}_{3} \mathrm{CCl}_{3}+\mathrm{h} v$ & $\rightarrow$ & $3 \mathrm{Cl}+$ products & $J_{\mathrm{CH}_{3} \mathrm{CCl}_{3}}$ & 247 \\
\hline $\mathrm{CFCl}_{3}+\mathrm{h} v$ & $\rightarrow$ & $3 \mathrm{Cl}+$ products & $J_{\mathrm{CFCl}_{3}}$ & 256 \\
\hline $\mathrm{CF}_{2} \mathrm{Cl}_{2}+\mathrm{h} v$ & $\rightarrow$ & $2 \mathrm{Cl}+$ products & $J_{\mathrm{CF}_{2} \mathrm{Cl}_{2}}$ & 240 \\
\hline $\mathrm{CCl}_{4}+\mathrm{h} v$ & $\rightarrow$ & $4 \mathrm{Cl}+$ products & $J_{\mathrm{CCl}_{4}}$ & 274 \\
\hline $\mathrm{HOCl}+\mathrm{h} v$ & $\rightarrow$ & $\mathrm{Cl}+\mathrm{OH}$ & $J_{\mathrm{HOCl}}$ & 435 \\
\hline $\mathrm{Cl}_{2} \mathrm{O}_{2}+\mathrm{h} v(+\mathrm{M})$ & $\rightarrow$ & $2 \mathrm{Cl}+\mathrm{O}_{2}(+\mathrm{M})$ & $J_{\mathrm{Cl}_{2} \mathrm{O}_{2}}$ & 400 \\
\hline $\mathrm{HCl}+\mathrm{h} v$ & $\rightarrow$ & $\mathrm{Cl}+\mathrm{H}$ & $J_{\mathrm{HCl}}$ & 222 \\
\hline \multicolumn{5}{|l|}{ Odd nitrogen } \\
\hline $\mathrm{NO}_{2}+\mathrm{h} v$ & $\rightarrow$ & $\mathrm{NO}+\mathrm{O}\left({ }^{3} \mathrm{P}\right)$ & $J_{\mathrm{NO}_{2}}$ & 420 \\
\hline $\mathrm{NO}+\mathrm{h} v$ & $\rightarrow$ & $\mathrm{N}+\mathrm{O}\left({ }^{3} \mathrm{P}\right)$ & $J_{\mathrm{NO}}$ & 191 \\
\hline $\mathrm{NO}_{3}+\mathrm{h} v$ & $\rightarrow$ & $\mathrm{NO}_{2}+\mathrm{O}\left({ }^{3} \mathrm{P}\right)$ & $J_{\mathrm{NO}_{3} \mathrm{~A}}$ & 640 \\
\hline $\mathrm{NO}_{3}+\mathrm{h} v$ & $\rightarrow$ & $\mathrm{NO}+\mathrm{O}_{2}$ & $J_{\mathrm{NO}_{3} \mathrm{~B}}$ & 640 \\
\hline $\mathrm{N}_{2} \mathrm{O}_{5}+\mathrm{h} v$ & $\rightarrow$ & $\mathrm{NO}_{2}+\mathrm{NO}_{3}$ & $J_{\mathrm{N}_{2} \mathrm{O}_{5}}$ & 380 \\
\hline $\mathrm{HNO}_{3}+\mathrm{h} v$ & $\rightarrow$ & $\mathrm{NO}_{2}+\mathrm{OH}$ & $J_{\mathrm{HNO}_{3}}$ & 320 \\
\hline $\mathrm{HO}_{2} \mathrm{NO}_{2}+\mathrm{h} v$ & $\rightarrow$ & $\mathrm{NO}_{2}+\mathrm{HO}_{2}$ & $J_{\mathrm{HO}_{2} \mathrm{NO}_{2}}$ & 330 \\
\hline $\mathrm{ClONO}_{2}+\mathrm{h} v$ & $\rightarrow$ & $\mathrm{Cl}+\mathrm{NO}_{3}$ & $J_{\mathrm{ClONO}_{2}}$ & 440 \\
\hline \multicolumn{5}{|l|}{ Odd hydrogen } \\
\hline $\mathrm{H}_{2} \mathrm{O}+\mathrm{h} v$ & $\rightarrow$ & $\mathrm{H}+\mathrm{OH}$ & $J_{\mathrm{H}_{2} \mathrm{O}}$ & 203 \\
\hline $\mathrm{H}_{2} \mathrm{O}_{2}+\mathrm{h} v$ & $\rightarrow$ & $2 \mathrm{OH}$ & $J_{\mathrm{H}_{2} \mathrm{O}_{2}}$ & 355 \\
\hline $\mathrm{CH}_{2} \mathrm{O}+\mathrm{h} v$ & $\rightarrow$ & $\mathrm{H}_{2}+\mathrm{CO}$ & $J_{\mathrm{CH}_{2} \mathrm{OA}}$ & 365 \\
\hline $\mathrm{CH}_{2} \mathrm{O}+\mathrm{h} v\left(+\mathrm{O}_{2}\right)$ & $\rightarrow$ & $\mathrm{H}+\mathrm{CO}+\mathrm{HO}_{2}$ & $J_{\mathrm{CH}_{2} \mathrm{OB}}$ & 330 \\
\hline $\mathrm{CH}_{3} \mathrm{O}_{2} \mathrm{H}+\mathrm{h} v$ & $\rightarrow$ & $\mathrm{CH}_{3} \mathrm{O}+\mathrm{OH}$ & $J_{\mathrm{CH}_{3} \mathrm{O}_{2} \mathrm{H}}$ & 370 \\
\hline
\end{tabular}

\section{Appendix B}

Numerical method used to calculate the rates of change of chemical species

Consider the continuity equation

$\frac{\partial q}{\partial t}=P-L q$

where $q$ is the number density $\left(\mathrm{cm}^{-3}\right)$ for a given species; $P$ is the chemical production term $\left(\mathrm{cm}^{-3} \mathrm{~s}^{-1}\right)$ and $L$ is the chemical loss frequency $\left(\mathrm{s}^{-1}\right)$. The prognostic equations for chemical species and families are integrated using standard methods, either Euler backward formulation $q_{\text {new }}=\frac{q_{\text {old }}+P_{\text {old }} \Delta t}{1+L_{\text {old }} \Delta t}$

or a semi-analytic exponential approach

$q_{\text {new }}=q_{\text {old }} \mathrm{e}^{-L \Delta t}+\frac{P_{\text {old }}}{L_{\text {old }}}\left(1-\mathrm{e}^{-L_{\text {old }} \Delta t}\right)$.

The individual members of chemical families are integrated either with the above exponential or a steadystate approach

$q=\frac{P}{L}$

for species with $(L \Delta t \gg 1)$. These species are not transported in the model, although the families to which they belong, are.

At each time-step, the chemical solution technique is as follows: the odd oxygen family is partitioned adopting photochemical steady state for $\mathrm{O}\left({ }^{3} \mathrm{P}\right)$ and $\mathrm{O}\left({ }^{1} \mathrm{D}\right)$. The coupling of $\mathrm{ClOX}$ and $\mathrm{NOX}$ by $\mathrm{ClONO}_{2}$ requires a special treatment for the partitioning of the $\mathrm{NO}_{x}$ and $\mathrm{ClO}_{x}$ families into the constituent parts. The change of ClOX and NOX by heterogeneous reactions (Table 1 ) is calculated first to obtain $\mathrm{ClOX}_{\text {het }}$ and $\mathrm{NOX}_{\text {het }}$ using Eq. (2). In the next step, $\mathrm{ClOX}$ is replaced by $\mathrm{ClOX}_{\text {het }}$ on the left-hand side of the family definition equation, and each family member is expressed by one of the aforementioned numerical approaches depending on its lifetime, in terms of $\mathrm{ClO}, \mathrm{NO}_{2}, \mathrm{O}_{x}$ and $\mathrm{HO}_{x}$ species. For $\mathrm{ClONO}_{2}$ and $\mathrm{ClOH}$, Eq. (2) is used, for $\mathrm{Cl}_{2} \mathrm{O}_{2}$ Eq. (1) with $[\mathrm{ClO}]_{\text {old }} \times[\mathrm{ClO}]$ in the production term, and for $\mathrm{Cl}$ Eq. (3). This yields a functional relationship between $\mathrm{ClO}$ and $\mathrm{NO}_{2}\left([\mathrm{ClO}]=a /\left(b+c\left[\mathrm{NO}_{2}\right]\right)\right)$. The partitioning of the NOX family is obtained in an analogous way, solving for $\mathrm{NO}_{2}$ after integration of the heterogeneous reactions affecting the family. Here, for $\mathrm{HNO}_{4}$ and $\mathrm{N}_{2} \mathrm{O}_{5}$ Eq. (2) is used, while $\mathrm{N}, \mathrm{NO}$ and $\mathrm{NO}_{3}$ are assumed to be in steady state. The definition equation for NOX can then be written as a quadratic equation for [ $\left.\mathrm{NO}_{2}\right]$. Expressing $\mathrm{ClO}$ by $\mathrm{NO}_{2}$ in the NOX equation using the relation derived in the $\mathrm{ClOX}$ family leads to a cubic equation for $\mathrm{NO}_{2}$. Its coefficients behave in such a manner that it has only one real positive solution, which is computed with the Newton method. The other NOX and ClOX family members can then be obtained successively. These species are next used for integrating 
and partitioning the odd hydrogen family through a quadratic equation for $\mathrm{HO}_{2}$ (based on Brühl, 1987). Finally, the chemical source and sink terms are calculated for each family or for each transported species. These terms are used to perform the time integration of long-lived species and families, including transport term contribution with a check for the mass balance of $\mathrm{ClX}$ and NOY. More details are given in Steil (1997).

\section{References}

Blom, C. E., H. Fischer, N. Glatthor, T. Gulde, M. Höpfner, and C. Piesch, Spatial and temporal variability of $\mathrm{ClONO}_{2}, \mathrm{HNO}_{3}$, and $\mathrm{O}_{3}$ in the arctic winter of 1992/1993 as obtained by airborne infrared emission spectroscopy, J. Geophys. Res., 100, 91019114, 1995.

Bojkov, R. D., and V. E. Fioletov, Estimating the global ozone characteristics during the last 30 years, J. Geophys. Res., 100, 16537-16551, 1995.

Boucher, O., and U. Lohmann, The sulphate-CCN-cloud albedo effect. A sensitivity study with two general circulation models, Tellus, 47B, 281-300, 1995.

Brühl, C., Ein effizientes Modell für globale Klima- und Luftzusammensetzungsänderungen durch menschliche Aktivitäten, Ph. D. Thesis, Fachbereich Physik, Johannes-Gutenberg Universität, Mainz, 1987.

Brühl, C., and P. J. Crutzen, On the disproportionate role of tropospheric ozone as a filter against UV-B radiation, Geophys. Res. Lett., 16, 703-706, 1989.

Brühl, C., and P. J. Crutzen, MPIC two-dimensional model, in The atmospheric effects of stratospheric aircraft: report of the 1992 models and measurements workshop, Eds. M. Prather and E. Remsberg, NASA Reference Publication 1292, Vol. I, Washington D. C., 103-104, 1993.

Brühl, C., K. Carslaw, J. U. Grooß, J. M. Russell III, and R. Müller, Chlorine activation and ozone depletion in the arctic vortex of the four recent winters using a trajectory box model and HALOE satellite observations, in Proc. XVIII Quadrennial Ozone Symp., L'Aquila, 12-21 September 1996, in press, 1997.

Cariolle, D, and M. Deque, Southern hemisphere medium-scale waves and total ozone disturbances in a spectral general circulation model, J. Geophys. Res., 91, 10825-10846, 1986.

Cariolle, D., A. Lassere-Bigorry, and J.-F. Royer, A general circulation model simulation of the springtime Antarctic ozone decrease and its impact on mid-latitudes, J. Geophys. Res., 95, 1883-1898, 1990.

Chipperfield, M. P., J. A. Pyle, C. E. Blom, N. Glatthor, M. Höpfner, T. Gulde, C. Piesch, and P. Simon, The variability of $\mathrm{ClONO}_{2}$ and $\mathrm{HNO}_{3}$ in the Arctic polar vortex: comparison of Transall Michelson interferometer for passive atmospheric sounding measurements and three-dimensional model results, $J$. Geophys. Res., 100, 9115-9129, 1995.

Cox, R. A., A. R. MacKenzie, R. Müller, T. Peter, and P. J. Crutzen, Activation of chlorine by reactions in liquid sulphuric acid, Geophys. Res. Lett., 21, 1439-1442, 1994.

Cubasch, U., K. Hasselmann, H. Höck, E. Maier-Reimer, U. Mikolajewicz, B. D. Santer, and R. Sausen, Time-dependent greenhouse warming computations with a coupled oceanatmosphere model, Clim. Dyn., 8, 55-69, 1992.

Cubasch, U., G. Hegerl, A. Hellbach, H. Höck, U. Mikolajewicz, B. D. Santer, and R. Voss, A climate simulation starting in 1935 , Clim. Dyn., 11, 71-84, 1995.

Curtis, A. R., and W. P. Sweetenham, Facsimile/Chekmat User's Manual, Computer Science and System Division, Harwell Laboratory, Oxford, England, 1987.

DeMore, W. B., S. P. Sander, D. M. Golden, R. F. Hampson, M. J. Kurylo, C. J. Howard, A. R. Ravishankara, C. E. Kolb, and M. J.
Molina, Chemical kinetics and photochemical data for use in stratospheric modeling, JPL publication 92-20, Pasadena, Calif., 1992.

DeMore, W. B., S. P. Sander, D. M. Golden, R. F. Hampson, M. J. Kurylo, C. J. Howard, A. R. Ravishankara, C. E. Kolb, and M. J. Molina, Chemical kinetics and photochemical data for use in stratospheric modeling, JPL publication 94-26, Pasadena, Calif., 1994.

Dentener, F. J., and P. J. Crutzen, Reaction of $\mathrm{N}_{2} \mathrm{O}_{5}$ on tropospheric aerosol: impact on the global distribution of $\mathrm{NO}_{x}, \mathrm{O}_{3}$, and $\mathrm{OH}$, J. Geophys. Res., 98, 7149-7163, 1993.

Dianov-Klokov, V. I., and L. N. Yurganov, A spectroscopic study of the global space-time distribution of atmospheric carbon monoxide, Tellus, 33, 262-273, 1981.

Dianov-Klokov, V. I., L. N. Yurganov, E. I. Grecho, and A. V. Dzhola, Spectroscopic measurements of atmospheric carbon monoxide and methane. 1: Latitudinal distribution, J. Atmos. Chem., 8, 139-151, 1989.

Douglass, A. R., M. R. Schoeberl, R. S. Stolarski, J. W. Waters, J. M. Russell III, A. E. Roche, and S. T. Massie, Interhemispheric differences in springtime production of $\mathrm{HCl}$ and $\mathrm{ClONO}_{2}$ in the polar vortices, J. Geophys. Res., 100, 1396713978, 1995

Drdla, K., and R. P. Turco, Denitrification through PSC formation: a $1 \mathrm{D}$ model incorporating temperature oscillations, J. Atmos. Chem., 12, 318-366, 1991.

Dye, J., D. Baumgardner, B. W. Ganrud, and R. G. Knollenberg, Particle size distributions in Arcticpolar stratospheric clouds, J. Geophys. Res., 97, 8015-8034, 1992.

Eckman, R. S., W. L. Grose, R. E. Turner, W. T. Blackshear, J. M. Russell III, L. Froidevaux, J. W. Waters, J. B. Kumer, and A. E. Roche, Stratospheric trace constituents simulated with a threedimensional general circulation model: comparison with UARS data, J. Geophys. Res., 100, 13951-13966, 1995.

Eckman, R. S., W. L. Grose, R. E. Turner, and W. T. Blackshear, Polar ozone depletion: a three-dimensional chemical modeling study of its long-term global impact, J. Geophys. Res., 101, 22977-22989, 1996.

Elson, L. S., W. G. Read, J. W. Waters, P. W. Mote, J. S. Kinnersley, and R. S. Harwood, Space-time variations in water vapour as observed by the UARS Microwave Limb Sounder, J. Geophys. Res., 101, 9001-9015, 1996.

Feichter, H., R. A. Brost, and M. Heimann, Three-dimensional modeling of the concentration and deposition of ${ }^{210} \mathrm{~Pb}$ aerosols, J. Geophys. Res., 96, 22447-22460, 1991.

Graf, H. F., J. Perlwitz, I. Kirchner, and I. Schult, Recent northern winter climate trends due to ozone changes and increased greenhouse gas forcing? Beitr. Phys. Atmos., 68, 233248, 1995

Grewe, V., Der Einfluß chemischer und dynamischer Prozesse auf die Ozonverteilung der Nordhemisphäre, $\mathrm{Ph}$. D. Thesis, Institut für Physik der Atmosphäre, Deutsche Forschungsanstalt für Luftund Raumfahrt e.V. (DLR), Forschungsbericht 97-09, 1997.

Groob, J.-U., Modelling of stratospheric chemistry based on HALOE/UARS satellite data, $\mathrm{Ph}$. D. Thesis, Fachbereich Physik, Johannes-Gutenberg Universität, Mainz, 1996.

Grooß, J. -U., R. B. Pierce, P. J. Crutzen, W. L. Grose, and J. M. Russell III, Reformation of chlorine reservoirs in southern hemisphere polar spring, J. Geophys. Res., 102, 13141-13152, 1997.

Grose, W. L., J. E. Nealy, R. E. Turner, and W. T. Blackshear, Modeling the transport of chemically active constituents in the stratosphere, in: Transport processes in the middle atmosphere, Eds. G. Visconti and R. Garcia, D. Reidel, Norwell, Mass., pp. 229-250, 1987.

Hanson, D. R., and K. Mauersberger, Laboratory studies of nitric acid trihydrate: implications for the south polar stratosphere, Geophys. Res. Lett., 15, 855-858, 1988.

Hanson, D. R., and A. R. Ravishankara, The reaction probabilities of $\mathrm{ClONO}_{2}$ and $\mathrm{N}_{2} \mathrm{O}_{5}$ on 40 to $75 \%$ sulfuric acid solutions, J. Geophys. Res., 96, 17307-17314, 1991. 
Harries, J. E., J. M. Russell III, A. F. Tuck, L. L. Gordley, P. Purcell, K. Stone, R. M. Bevilacqua, M. Gunson, G. Nedoluha, and W. A. Traub, Validation of measurements of water vapour from the Halogen Occultation Experiment (HALOE), J. Geophys. Res., 101, 10205-10216, 1996.

Hein, R., Inverse Modellierung des atmosphärischen MethanKreislaufs unter Verwendung eines dreidimensionalen Modells des Transports und der Chemie der Troposphäre, $\mathrm{Ph}$. D. Thesis, Institut für Meteorologie, Universität Hamburg, 1994.

IPCC Climate Change 1994, Radiative forcing of climate change and an evaluation of the IPCC IS92 emission scenarios, Intergovernmental panel on Climate Change, J. T. Houghton et al. (eds.), Cambridge University Press, Cambridge, 1995.

Köhler, I., R. Sausen, and R. Reinberger, Contributions of aircraft emissions to the atmosphere $\mathrm{NO}_{x}$ content, Atmos. Environ., 31, 1801-1818, 1997

König, W., R. Sausen, and F. Sielmann, Objective identification of cyclones, J. Clim., 6, 2217-2231, 1993.

Komhyr, W. D., S. J. Oltmans, P. R. Franchois, W. F. J. Evans, and W. A. Matthews, The latitudinal distribution of ozone to $35 \mathrm{~km}$ altitude from EEC ozonesonde observations, 1985-1987, in Ozone in the atmosphere, Eds. R. D. Bojkov and P. Fabian, A. Deepak, Hampton, Va., pp. 147-150, 1989.

Lefèvre, F., G. P. Brasseur, I. Folkins, A. K. Smith, and P. Simon, Chemistry of the 1991-1992 stratospheric winter: three-dimensional model simulations, J. Geophys. Res., 99, 8183-8195, 1994.

Lunkeit, F., R. Sausen, and J. M. Oberhuber, Climate simulations with the global coupled atmosphere-ocean model ECHAM2/ OPYC, Clim. Dyn., 12, 195-212, 1996.

Luo, B., T. Peter, and P. J. Crutzen, Freezing of stratospheric aerosol droplets, Geophys. Res. Lett., 21, 1447-1450, 1994.

Luo, B., U. K. Krieger, and T. Peter, Densities and refractive indices of ternary $\mathrm{H}_{2} \mathrm{SO}_{4}-\mathrm{HNO}_{3}-\mathrm{H}_{2} \mathrm{O}$ - solutions, Geophys. Res. Lett., 23, 3707-3710, 1996.

Manzini, E., and L. Bengtsson, Stratospheric climate and variability from a general circulation model and observations, Clim. Dyn., 12, 615-639, 1996

Mitchell, J. F. B., T. J. Johns, J. M. Gregory, and S. B. F. Tett, Climate response to increasing levels of greenhouse gases and sulphate aerosols, Nature, 376, 501-504, 1995.

Müller, R., P. J. Crutzen, J.-U. Grooß, C. Brühl, J. M. Russell III, and A. F. Tuck, Chlorine activation and ozone depletion in the Arctic vortex: observations by the Halogen Occultation Experiment on the Upper Atmosphere Research Satellite, J. Geophys. Res., 101, 12531-12554, 1996.

Naujokat, B., K. Petzoldt, K. Labitzke, R. Lenschow, B. Rajewski, M. Wiesner, and R. C. Wohlfart, The stratospheric winter 1991/ 92: the winter of the European Arctic Stratospheric Ozone Experiment, Beil. Berl. Wetterkarte, 68/92, Berlin, 1992.

Naujokat, B., K. Labitzke, R. Lenschow, B. Rajewski, M. Wiesner, and R. C. Wohlfart, The stratospheric winter 1994/95: a cold winter with a strong minor warming, Beil. Berl. Wetterkarte, $81 /$ 95, Berlin, 1995.

Oltmans, S. J., W. D. Komhyr, P. R. Frnachois, and W. A. Matthews, Tropospheric ozone: variations from surface and EEC ozonesonde observations, in Ozone in the atmosphere, Eds. R. D. Bojkov and P. Fabian, A. Deepak, Hampton, Va., pp. 539-543, 1989.

Pawson, S., B. Naujokat, and K. Labitzke, On the polar stratospheric cloud formation potential of the northern stratosphere, J. Geophys. Res., 100, 23215-23225, 1995.

Peter, T., C. Brühl, and P. J. Crutzen, Increase of the PSCformation probability caused by high-flying aircraft, Geophys. Res. Lett., 18, 1465-1468, 1991.

Ponater, M., S. Brinkop, R. Sausen, and U. Schumann, Simulating the global atmospheric response to aircraft water vapour emissions and contrails - a first approach using a GCM, Ann. Geophysicae, 14, 941-960, 1996.
Poole, L. R., and M. P. McCormick, Polar stratospheric clouds and the Antarctic ozone hole, J. Geophys. Res., 93, 8423-8430, 1988.

Poole, L. R., and M. C. Pitts, Polar stratospheric cloud climatology based on Stratospheric Aerosol Measurement II observations from 1978 to 1989, J. Geophys. Res., 99, 13083-13089, 1994.

Rasch, P. J., and D. L. Williamson, Computational aspects of moisture transport in global models of the atmosphere, $Q$. J. R. Meteorol. Soc., 116, 1071-1090, 1990.

Rasch, P. J., B. A. Boville, and G. P. Brasseur, A three-dimensional general circulation model with coupled chemistry for the middle atmosphere, J. Geophys. Res., 100, 9041-9071, 1995.

Roeckner, E., K. Arpe, L. Bengtsson, S. Brinkop, L. Dümenil, M. Esch, E. Kirk, F. Lunkeit, M. Ponater, B. Rockel, R. Sausen, U. Schlese, S. Schubert, and M. Windelband, Simulation of the present-day climate with the ECHAM model: impact of model physics and resolution, Max-Planck-Institut für Meteorologie, Rep. No. 93, 1992.

Roelofs, G. J., and J. Lelieveld, Distribution and budget of $\mathrm{O}_{3}$ in the troposphere calculated with a chemistry general circulation model, J. Geophys. Res., 100, 20983-20998, 1995.

Russell III, J. M., L. L. Gordley, J. H. Park, S. R. Drayson, A. F. Tuck, J. E. Harries, R. J. Cicerone, P. J. Crutzen, and J. E. Frederick, The Halogen Occultation Experiment, J. Geophys. Res., 98, 10777-10797, 1993.

Santee, M. L., L. Froidevaux, G. L. Manney, W. G. Read, J. W. Waters, M. P. Chipperfield, A. E. Roche, J. B. Kumer, J. L. Mergenthaler, and J. M. Russell III, Chlorine deactivation in the lower stratospheric polar regions during late winter: results from UARS, J. Geophys. Res., 101, 18835-18859, 1996.

Sausen, R., Über die Verwendung von Korrekturverfahren in Zirkulationsmodellen, Zentrum für Meeres- und Klimaforschung, Universität Hamburg, Rep. No. 17, 1991.

Sausen, R., and I. Köhler, Simulating the global transport of nitrogen oxides emissions from aircraft, Ann. Geophysicae, 12, 394-402, 1994.

Sausen, R., K. Barthel, and K. Hasselmann, Coupled oceanatmosphere models with flux corrections, Clim. Dyn., 2, 154163,1988 .

Schlager, H., F. Arnold, D. J. Hofmann, and T. Deshler, Balloon observations of nitric acid aerosol formation in the arctic stratosphere: I gaseous nitric acid, Geophys. Res. Lett., 17, 1275-1278, 1990

Smith, A. K., Numerical simulation of global variations of temperature, ozone, and trace species in the stratosphere, J. Geophys. Res., 100, 1253-1269, 1995.

Steil, B., Modellierung der Chemie der Strato- und Troposphäre mit einem drei-dimensionalen Zirkulationsmodell, $\mathrm{Ph}$. D. Thesis, Institut für Meteorologie, Universität Hamburg, 1997.

Webster, C. R., R. D. May, D. W. Toohey, L. M. Avallone, J. G. Anderson, P. Newman, L. Lait, M. R. Schoeberl, J. W. Elkins, and K. R. Chan, Chlorine chemistry on polar stratospheric cloud particles in the arctic winter, Science, 261, 1130-1134, 1993.

Wofsy, S. C., R. J. Salawitch, M. B. McElroy, J. H. Yatteau, B. W. Gandrud, J. E. Dye, and D. Baumgardner, Condensation of $\mathrm{HNO}_{3}$ on falling ice particles: mechanism for denitrification of the polar stratosphere, Geophys. Res. Lett., 17, 449-453, 1990.

World Meteorological Organization (WMO), Scientific assessment of ozone depletion: 1991, Rep. No. 25, Geneva, Switzerland, 1992.

World Meteorological Organization (WMO), Scientific assessment of ozone depletion: 1994, Global ozone research and monitoring project, Rep. No. 37, Geneva, Switzerland, 1995.

Zimmermann, P. H., MOGUNTIA: a handy global tracer model, in Air pollution modeling and its implications, Ed. H. van Dop, VI. NATO/CCMS, Plenum, New York, 593-608, 1988. 